\title{
Laterality and region-specific tau phosphorylation correlate with PTSD-related behavioral traits in rats exposed to repetitive low-level blast
}

Georgina Perez Garcia ${ }^{1,2+}$, Rita De Gasperi ${ }^{1,3+}$, Miguel A. Gama Sosa ${ }^{3,4}$, Gissel M. Perez ${ }^{1}$, Alena Otero-Pagan ${ }^{1}$, Dylan Pryor ${ }^{1}$, Rania Abutarboush ${ }^{5,6}$, Usmah Kawoos ${ }^{5,6}$, Patrick R. Hof ${ }^{7,8,9}$, Dara L. Dickstein ${ }^{10,11}$,

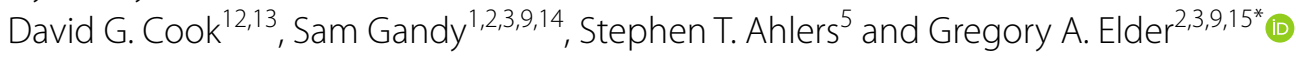

\begin{abstract}
Military veterans who experience blast-related traumatic brain injuries often suffer from chronic cognitive and neurobehavioral syndromes. Reports of abnormal tau processing following blast injury have raised concerns that some cases may have a neurodegenerative basis. Rats exposed to repetitive low-level blast exhibit chronic neurobehavioral traits and accumulate tau phosphorylated at threonine 181 (Thr181). Using data previously reported in separate studies we tested the hypothesis that region-specific patterns of Thr181 phosphorylation correlate with behavioral measures also previously determined and reported in the same animals. Elevated p-tau Thr181 in anterior neocortical regions and right hippocampus correlated with anxiety as well as fear learning and novel object localization. There were no correlations with levels in amygdala or posterior neocortical regions. Particularly striking were asymmetrical effects on the right and left hippocampus. No systematic variation in head orientation toward the blast wave seems to explain the laterality. Levels did not correlate with behavioral measures of hyperarousal. Results were specific to Thr181 in that no correlations were observed for three other phospho-acceptor sites (threonine 231, serine 396, and serine 404). No consistent correlations were linked with total tau. These correlations are significant in suggesting that p-tau accumulation in anterior neocortical regions and the hippocampus may lead to disinhibited amygdala function without p-tau elevation in the amygdala itself. They also suggest an association linking blast injury with tauopathy, which has implications for understanding the relationship of chronic blast-related neurobehavioral syndromes in humans to neurodegenerative diseases.
\end{abstract}

Keywords: Animal model, Behavior, Blast, Laterality, Rat, Tau, Traumatic brain injury

*Correspondence: gregory.elder@va.gov

${ }^{\dagger}$ Georgina Perez Garcia and Rita De Gasperi have contributed equally to this work

2 Department of Neurology, Icahn School of Medicine At Mount Sinai, One Gustave Levy Place, New York, NY 10029, USA

Full list of author information is available at the end of the article

\section{Introduction}

Accumulation of abnormally phosphorylated tau is a feature of many human neurodegenerative diseases, collectively referred to as tauopathies [51]. In diseases such as Alzheimer's disease, the frontotemporal dementias and primary age-related tauopathy, these accumulations form a range of aggregated and oligomeric structures, with the best-known example being the neurofibrillary tangle (NFT) [51]. Tauopathy is a component of the recently original author(s) and the source, provide a link to the Creative Commons licence, and indicate if changes were made. The images or other third party material in this article are included in the article's Creative Commons licence, unless indicated otherwise in a credit line to the material. If material is not included in the article's Creative Commons licence and your intended use is not permitted by statutory regulation or exceeds the permitted use, you will need to obtain permission directly from the copyright holder. To view a copy of this licence, visit http://creativecommons.org/licenses/by/4.0/. The Creative Commons Public Domain Dedication waiver (http://creativeco mmons.org/publicdomain/zero/1.0/) applies to the data made available in this article, unless otherwise stated in a credit line to the data. 
formulated multiplex of genetic and molecular mechanisms that contribute to brain degeneration [91]. The mechanism(s) of abnormal tau hyperphosphorylation in these disorders remains incompletely understood, as does the role of various protein kinases and protein phosphatases that control tau phosphorylation.

Traumatic brain injury (TBI) is a risk factor for later development of neurodegenerative diseases that may have various underlying pathologies. Chronic traumatic encephalopathy (CTE) is one form of TBI-related dementia $[18,19,34]$. CTE is most often associated with repetitive mild TBI (mTBI) and is characterized pathologically by aggregation of hyperphosphorylated tau into NFTs, which occur in a characteristic pattern [68]. CTE can only be diagnosed definitively at autopsy but may be suspected clinically when a progressive cognitive/behavioral syndrome develops following repetitive mTBIs [34]. Recent ultrastructural evidence indicates that CTE tauopathy is distinct from other tauopathies, perhaps because in CTE novel moieties of either lipid or carbohydrate are incorporated into tau [30]. Computational modeling has further suggested that mechanical strain factors may explain why the pathology is most prominent in the depths of cortical sulci [37].

TBI is a long-standing concern in military life and has recently received increased attention because of the conflicts in Iraq and Afghanistan where $10-20 \%$ of deployed troops suffered a TBI [27]. While these TBIs occurred through various mechanisms, blast-related injuries resulting from exposures to mortars, artillery shells and improvised explosive devices were the major causes with repetitive mild injuries common [27]. Concerns also exist over potential adverse effects of subclinical blast exposures, which are common for many service members in combat as well as non-combat settings [29].

A number of reports have appeared of pathologically confirmed CTE in military veterans following blast injury $[39,59,69,76]$. Tau pathology has also been prominent in veterans with chronic cognitive and behavioral syndromes following blast exposure even when classic CTE pathology was not present [46]. Positron emission tomography (PET) scanning using the tau ligand $\left[{ }^{18} \mathrm{~F}\right]$ AV1451 has shown excessive ligand retention in veterans with a history of blast exposure who suffer from chronic cognitive and behavioral syndromes [21, 71, 84]. Others have noted increased plasma tau concentrations in recently deployed veterans with a history of TBI, that correlated with symptom severity [75]. While the relative risk of CTE following blast exposure is unknown, concern has been raised in the most recent veterans due to the frequency of repetitive mTBI [27].

Rats exposed to a repetitive low-level blast exposure protocol designed to mimic an mTBI or subclinical blast exposure develop a variety of cognitive and post-traumatic stress disorder (PTSD)-related behavioral traits $[78,81]$. These traits develop in a delayed manner and become chronic and persistent being present for at least 1 year after blast exposure [78, 81].

Although not as well appreciated as in humans, rats and mice have been known to exhibit paw preference and hemispheric laterality for complex behavioral functions since the 1970s [20]. Hemispheric dominance in particular affects spatial memory in rodents $[50,89]$. The brain dopaminergic system, which is disrupted by blast exposure [87] also shows well-established lateralization patterns $[9,14,96]$. In a prior study we reported that rats exposed to repetitive low-level blast exposure accumulate abnormal levels of phosphorylated tau (p-tau) with a laterality and regionally specific pattern [21]. Here we correlated levels of p-tau measured in this prior study [21] with behavioral parameters previously assessed in the same animals [81]. We report that p-tau levels correlate with blast-induced behavioral traits.

\section{Materials and methods}

\section{Experimental animals}

Adult male Long Evans hooded rats (250-350 g; 10 weeks of age; Charles River Laboratories International, Wilmington, MA, USA) were used. All studies involving animals were reviewed and approved by the Institutional Animal Care and Use Committees of the Walter Reed Army Institute of Research (WRAIR)/Naval Medical Research Center and the James J. Peters VA Medical Center. Studies were conducted in compliance with the Public Health Service policy on the humane care and use of laboratory animals, the NIH Guide for the Care and Use of Laboratory Animals, and all applicable Federal regulations governing the protection of animals in research.

\section{Blast overpressure exposure}

Rats were exposed to overpressure injury using the WRAIR shock tube, which simulates the effects of airblast exposure under experimental conditions [1]. The shock tube has a $30.48 \mathrm{~cm}$ circular diameter and is a $5.94 \mathrm{~m}$-long steel tube divided into a 77.4-cm compression chamber that is separated from a $5.18 \mathrm{~m}$ expansion chamber. The compression and expansion chambers are separated by polyethylene Mylar ${ }^{\mathrm{TM}}$ sheets (Du Pont, Wilmington, DE, USA) that control the peak pressure generated. The peak pressure at the end of the expansion chamber was determined by piezoresistive gauges specifically designed for pressure-time (impulse) measurements (Model 102M152, PCB, Piezotronics, Depew, NY, USA). 
Individual rats were anesthetized using an isoflurane gas anesthesia system consisting of a vaporizer, gas lines and valves and an activated charcoal scavenging system adapted for use with rodents. Rats were placed into a polycarbonate induction chamber, which was closed and immediately flushed with $5 \%$ isoflurane in air mixture for two minutes. Rats were placed into a cone shaped plastic restraint device and then placed in the shock tube. Movement was further restricted during the blast exposure using $1.5 \mathrm{~cm}$ diameter flattened rubber tourniquet tubing. Three tourniquets were spaced evenly to secure the head region, the upper torso and lower torso while the animal was in the plastic restraint cone. The end of each rubber tourniquet was threaded through a toggle and run outside of the exposure cage where it was tied to affix the animal firmly and prevent movement during the blast overpressure exposure without restricting breathing. Rats were randomly assigned to sham or blast conditions and were placed in the shock tube lying prone with the plane representing a line from the tail to the nose of the body in line with the longitudinal axis of the shock tube with the head placed more upstream. Further details of the physical characteristics of the blast wave were described previously [1]. Blast exposed animals received $74.5 \mathrm{kPa}$ (equivalent to $10.8 \mathrm{psi}$, duration $4.8 \mathrm{~ms}$, impulse $175.8 \mathrm{kPa}$ " $\mathrm{ms}$ ) exposures administered one exposure per day for three consecutive days. Control (sham-exposed) animals were treated identically including receiving anesthesia and being placed in the blast tube but did not receive a blast exposure. Within 10 days after the last blast or sham exposure animals were transported in a climate-controlled van from the WRAIR to the James J. Peters VA Medical Center (Bronx, NY, USA). Animals left in the morning from the WRAIR and arrived in the afternoon of the same day at the James J. Peters VA Medical Center, where all other procedures were performed.

\section{Animal housing}

At the James J. Peters VA Medical Center, animals were housed at a constant $70-72^{\circ} \mathrm{F}$ temperature with rooms on a 12:12 h light cycle with lights on at $7 \mathrm{AM}$. All subjects were individually housed in standard clear plastic cages equipped with Bed-O'Cobs laboratory animal bedding (The Andersons, Maumee, Ohio, USA) and EnviroDri nesting paper (Sheppard Specialty Papers, Milford, NJ, USA). Access to food and water was ad libitum. Subjects were housed on racks in random order to prevent rack position effects. Cages were coded to allow maintenance of blinding to groups during behavioral testing.

\section{Behavioral testing Elevated zero maze}

The apparatus consisted of a circular black Plexiglas runway $121.92 \mathrm{~cm}$ in diameter and raised $76 \mathrm{~cm}$ off the floor (San Diego Instruments, San Diego, CA, USA). The textured runway itself was $5.08 \mathrm{~cm}$ across and divided equally into alternating quadrants of open runway enclosed only by a $1.27-\mathrm{cm}$ lip and closed runway with smooth 15.24-cm walls. All subjects received a 5-min trial beginning in a closed arc of the runway. During each trial, subjects were allowed to move freely around the runway, with all movement tracked automatically by a video camera placed on the ceiling directly above the maze. Data were analyzed by ANYMAZE (San Diego Instruments, San Diego CA, USA) yielding measures of total movement time and distance for the entire maze, as well as time spent and distance traveled in each of the individual quadrants. From the quadrant data, measures of total open and closed arc times, latency to enter an open arc, total open arm entries and latency to completely cross an open arc between two closed arcs were calculated. Subject position was determined by centroid location.

\section{Light/dark escape}

A light/dark escape task was run in Versamax activity cages with opaque black Plexiglas boxes enclosing the left half of the interiors so that only the right sides were illuminated. Animals began in the dark side and were allowed to freely explore for $10 \mathrm{~min}$ with access to the right (light) side through an open doorway located in the center of the monitor. Subject side preference and emergence latencies were tracked by centroid location with all movement automatically tracked and quantified. Lightside emergence latency, time to reach the center of the lighted side (light side center latency) and percent total light-side duration were calculated from beam breaks. All equipment was wiped clean between tests.

\section{Contextual and cued fear conditioning}

Sound-attenuated isolation cubicles (Coulbourn Instruments, Holliston, MA, USA) were utilized. Each cubicle was equipped with a grid floor for delivery of the unconditioned stimulus (US) and overhead cameras. All aspects of the test were controlled and monitored by the Freeze Frame conditioning and video tracking system (Actimetrics, Coulbourn Instruments). During training the chambers were scented with almond extract, lined with white paper towels, had background noise generated by a small fan and were cleaned before and between trials with $70 \%$ ethanol. Each subject was placed inside the conditioning chamber for $2 \mathrm{~min}$ before the onset of a conditioned 
stimulus (CS; an $80 \mathrm{~dB}, 2 \mathrm{kHz}$ tone), which lasted for $20 \mathrm{~s}$ with a co-terminating $2 \mathrm{~s}$ footshock $(0.7 \mathrm{~mA}$; unconditioned stimulus [US]). A total of three tone/shock pairings were administered separated by one min. Each rat remained in the chamber for an additional $40 \mathrm{~s}$ following the last CS-US pairing before being returned to its home cage. Freezing was defined as a lack of movement (except for respiration) in each 10-s interval. Minutes 0-2 during the training session were used to measure baseline freezing. Contextual fear memory testing was performed $24 \mathrm{~h}$ after the training session by measuring freezing behavior during a 4-min test in the conditioning chamber under conditions identical to those of the training session with the exception that no footshock or tone (CS or US) was presented. Animals were returned to their home cage for another $24 \mathrm{~h}$ at which time cued conditioning was tested. To create a new context with different properties, the chambers were free of background noise (fan turned off), lined with blue paper towels, scented with lemon extract and cleaned before and during all trials with isopropanol. Each subject was placed in this novel context for $2 \mathrm{~min}$ and baseline freezing was measured, followed by exposure to the CS (20-s tone) at 120 and $290 \mathrm{~s}$.

\section{Novel object recognition}

Rats were habituated to the arena $(90 \mathrm{~cm}$ length $\times 60 \mathrm{~cm}$ width $\times 40 \mathrm{~cm}$ height) for $20 \mathrm{~min}, 24 \mathrm{~h}$ before training. On the training day, two identical objects were placed on opposite ends of the empty arena, and the rat was allowed to freely explore the objects for $7 \mathrm{~min}$. After a 1-h delay, during which the rat was held in its home cage, one of the two familiar objects was replaced with a novel one, and the rat was allowed to freely explore the familiar and novel object for 5 min to assess short-term memory (STM). After a 24-h delay, during which the rat was held in its home cage, one of the two familiar objects was replaced with a novel one different from the ones used during the short-term memory test. The rat was allowed to explore freely the familiar and novel object for 5 min to assess long-term memory (LTM). Raw exploration times for each object were expressed in seconds. Object exploration was defined as sniffing or touching the object with the vibrissae or when the animal's head was oriented toward the object with the nose placed at a distance of less than $2 \mathrm{~cm}$ from the object. All sessions were recorded by video camera (Sentech, Carrollton TX, USA) and analyzed with ANYMAZE software (San Diego Instruments). In addition, offline analysis by an investigator blind to the blast-exposed status of the animals was performed. Objects to be discriminated were of different size, shape and color and were made of plastic or metal material. The objects consisted of a $330 \mathrm{ml}$ soda can, a metal box and a cup and a plastic tube. All objects were cleaned with $70 \%$ ethanol between trials. A discrimination index was calculated with the formula: time exploring the novel object minus time exploring the familiar object/total exploration time X 100.

\section{Novel object localization}

Novel location recognition was used to assess spatial recognition and visual memory using methods previously described $[47,82]$ that were modified from Yolken et al. [107]. Briefly, 24 h before training, rats were habituated for $20 \mathrm{~min}$ to the same empty arena used for the novel object recognition task. The arena was situated in a welllit room allowing the rats to see distal visual cues. On the training day, two identical objects were placed in specific locations and the rat was allowed to explore freely the objects for $7 \mathrm{~min}$. The test trial was performed after a 1-h delay during which one object was moved to a different location in the arena and the rat was allowed to explore for $5 \mathrm{~min}$. Time spent investigating the objects in their original or novel locations was recorded. During sessions the arena and objects were cleaned before and between trials with $70 \%$ ethanol. A discrimination index was calculated as above.

\section{Prepulse inhibition and acoustic startle}

Startle magnitude and sensory gating were examined in a 40-trial prepulse inhibition assay (San Diego Instruments). Animals were placed in isolation chambers inside closed Plexiglas tubes, each of which was mounted on a platform resting on an accelerometer. Following a $5 \mathrm{~min}$ habituation period with $74 \mathrm{~dB}$ background white noise, each animal received 40 randomized trials separated by 20-30 s. Trials consisted of 10 each of background readings taken at $74 \mathrm{~dB}$, startle trials with readings following $40 \mathrm{~ms} 125 \mathrm{~dB}$ tones, prepulse inhibition trials where the $125 \mathrm{~dB}$ tone was preceded $100 \mathrm{~ms}$ earlier by a $20 \mathrm{~ms}$ $79 \mathrm{~dB}$ tone and control trials consisting of only the $20 \mathrm{~ms}$ $79 \mathrm{~dB}$ prepulse. On all trials, maximum magnitude of the animal's startle (or other motion) was automatically recorded in $500 \mathrm{~ms}$ windows by an accelerometer. The tubes were rinsed clean between animals. Percent prepulse inhibition was calculated with the formula 100(startle response on acoustic prepulse plus pulse stimulus trials/pulse stimulus response alone trials) $X$ 100]. The first startle response was compared among groups.

\section{Regional brain dissection}

To dissect the various brain regions the cerebellum was removed and the brain was placed ventral side up and coronal cuts were made through the optic chiasm and anterior commissure. The neocortical tissue surrounding this piece of tissue was defined as the anterior cortex. To obtain the amygdala fraction, the tissue lateral to the 
hypothalamus between its caudal and rostral border and ventral to the rhinal sulcus on either side was dissected. After dissection of the amygdala the tissue was turned dorsal side up and the hippocampus dissected based on its typical morphology after the cerebral hemispheres were reflected out. The posterior neocortex included the remainder of the cerebral tissue after the removal of the caudate-putamen.

\section{Western blot analysis}

Tissue was homogenized in $0.1 \mathrm{M}$ Tris $\mathrm{HCl}$ buffer $\mathrm{pH}$ 7.4, containing $0.15 \mathrm{M} \mathrm{NaCl}, 5 \mathrm{mM}$ EDTA, $1 \%$ Triton $\mathrm{X} 100 / 0.1 \%$ SDS and a protease and phosphatase inhibitor cocktail (Halt, Pierce, Rockford IL, USA). Protein concentration was determined with the BCA reagent (Pierce). Protein samples $(50 \mu \mathrm{g})$ were separated by SDSPAGE and blotted onto polyvinylidene difluoride (PVDF) membranes (Millipore Corporation, Billerica, MA, USA). Blots were blocked with $50 \mathrm{mM}$ Tris $\mathrm{HCl}, \mathrm{pH} 7.6,0.15 \mathrm{M}$ $\mathrm{NaCl}, 0.1 \%$ Tween-20 (TBST), 5\% nonfat dry milk and probed overnight with the relevant primary antibody diluted in blocking solution. Blots were then incubated for $1.5 \mathrm{~h}$ with the appropriate horseradish peroxidase (HRP) conjugated secondary antibody (GE Healthcare Lifesciences, Piscataway, NJ, USA) diluted in blocking solution (1:7500) and bands were visualized by ECL Prime (GE Healthcare Lifesciences) and imaged with an Imager 600 workstation or by exposure to HyBlot CL film (Denville Scientific). The primary antibodies utilized are indicated in Table 1. All blots were sequentially reprobed with anti-tau to determine total tau levels and with anti glyceraldehyde 3-phosphate dehydrogenase (GAPDH) as loading controls. For reprobing, the membranes were stripped with Re-Blot Plus strong stripping solution (Millipore) or ReblotPlus Western blot stripping buffer (ThermoFisher) according to the manufacturer's instructions. Quantification was performed using Image Quant TL software (GE Healthcare Lifesciences). Phosphorylated tau (p-tau) levels were determined by adding the two major bands seen in Western blot and normalizing to total tau. For total tau quantitation the sum of the major and minor bands seen in Western blot was used. Total tau levels were normalized to GAPDH. All data were normalized relative to control samples.

\section{Statistical analysis}

Levels of p-tau isoforms and total tau were determined at 40 weeks after blast exposure in previous studies [21]. Tau levels were correlated with behavioral measures previously reported in the same blast-exposed and control (i.e. sham exposed) rats [80]. The time of behavioral testing in individual tasks is shown in Table 2. Data from five blast and five control animals were pooled for analysis.

\section{Table 2 Time following blast exposure when behavioral testing was begun}

\begin{tabular}{ll}
\hline Task & Time (weeks) \\
\hline Locomotor activity and open field & 28 \\
Light/dark emergence & 29 \\
Elevated zero maze & 30 \\
Novel object recognition & 31 \\
Novel location recognition & 33 \\
Acoustic startle/PPI & 34 \\
Cued and contextual fear conditioning & 35 \\
\hline
\end{tabular}

Original data was reported in Perez Garcia et al. [80]

Table 1 Primary antibodies used for Western blotting

\begin{tabular}{|c|c|c|c|c|}
\hline Antibody & Specificity & Source & Type & Dilution \\
\hline AT270 & Thr181 & $\begin{array}{l}\text { ThermoFisher } \\
\text { MN1050 }\end{array}$ & Mouse monoclonal & $1: 600$ \\
\hline Phospho-Tau (Thr181) & Thr181 & $\begin{array}{l}\text { Cell Signaling } \\
12885\end{array}$ & Rabbit monoclonal & $1: 1200$ \\
\hline Phospho-Tau (Thr181) & Thr181 & $\begin{array}{l}\text { ThermoFisher } \\
710561\end{array}$ & Rabbit oligoclonal & $1: 1000$ \\
\hline Phospho-Tau (Ser404) & Ser404 & $\begin{array}{l}\text { ThermoFisher } \\
\text { 44-758G }\end{array}$ & Rabbit polyclonal & $1: 1000$ \\
\hline PHF13 & Ser396 & $\begin{array}{l}\text { Cell Signaling } \\
9632\end{array}$ & Mouse monoclonal & $1: 1000$ \\
\hline Phospho-Tau (Thr231) & Thr231 & $\begin{array}{l}\text { ThermoFisher } \\
710126\end{array}$ & Rabbit oligoclonal & $1: 1000$ \\
\hline $\mathrm{CP} 13$ & Ser202 & Dr. Peter Davies & Mouse monoclonal & $1: 500$ \\
\hline AT8 & Ser202/Thr205 & $\begin{array}{l}\text { ThermoFisher } \\
\text { MN1020 }\end{array}$ & Mouse monoclonal & $1: 600$ \\
\hline Tau & Total tau & $\begin{array}{l}\text { Proteintech } \\
\text { 10274-1-AP }\end{array}$ & Rabbit polyclonal & $1: 600$ \\
\hline
\end{tabular}


Table 3 P-tau phosphorylation at Thr181 by brain region

\begin{tabular}{|c|c|c|c|c|c|c|c|c|}
\hline \multirow{2}{*}{$\begin{array}{l}\text { Brain region/time post- } \\
\text { blast exposure } \\
\text { Side }\end{array}$} & \multicolumn{2}{|c|}{ Anterior cortex } & \multicolumn{2}{|c|}{ Hippocampus } & \multicolumn{2}{|c|}{ Amygdala } & \multicolumn{2}{|c|}{ Posterior cortex } \\
\hline & Left & Right & Left & Right & Left & Right & Left & Right \\
\hline Six weeks & $N C$ & $\uparrow$ & NC & $\uparrow$ & ND & ND & ND & ND \\
\hline 40 weeks & $\uparrow$ & $\uparrow$ & NC & $\uparrow$ & $\mathrm{NC}$ & NC & NC & NC \\
\hline 52 weeks & $\uparrow$ & $\uparrow$ & NC & $\uparrow$ & ND & ND & ND & ND \\
\hline
\end{tabular}

$\uparrow=$ increased; $N C=$ no change; $N D=$ not determined. Phosphorylation at Thr181 was determined by Western blotting using the antibody AT270 in data previously reported [21]

Data sets were tested for normality in GraphPad Prism 8.0 (GraphPad Software) using the D'Agostino-Pearson normality test. Pearson's product-moment correlation coefficient, Kendall's tau-b, and Spearman's rho were calculated using SPSS v26 (IBM). Figures were prepared using GraphPad Prism 8.0 and Adobe Photoshop.

\section{Results}

Elevated p-tau threonine 181 (Thr181) in the anterior neocortex and right hippocampus correlates with behavioral measures of anxiety in blast-exposed rats Rats exposed to repetitive low-level blast develop chronic cognitive and PTSD-related behavioral trait that are present for at least 1 year following blast exposure [78, 81]. Previously we found that p-tau was chronically elevated in rats studied at 6 weeks, 40 weeks and 52 weeks following blast exposure [21]. Patterns are summarized in Table 3. With the anti p-tau antibody AT270 directed against phospho-Thr181, p-tau was increased in the right hippocampus but not the left hippocampus in all three cohorts. In the anterior cortex, p-tau was elevated on the right at all three time points while on the left it was increased at 40 weeks and 52 weeks but not at 6 weeks. P-tau was not changed in the amygdala or posterior cortex at any time point. Increased phosphorylation at p-Thr181 was confirmed using two additional anti-pThr181 antibodies besides AT270 [21].

The rats studied at 40 weeks following blast exposure were also previously characterized behaviorally [80] and found to exhibit the chronic cognitive and PTSD-related behavioral traits that are characteristic of this model [81]. Given the distinctive regional patterns and laterality of blast-induced tau phosphorylation we examined whether these patterns could be correlated with specific behavioral traits.

Figure 1 and Table 4 show correlation coefficients between p-Thr181 levels in four brain regions with behavioral measures in the elevated zero maze. In our previously published work, blast-exposed rats exhibited features of anxiety, moving less (move distance) as well as spending less time in the open arms and exhibiting a longer latency to cross between two open arms [80]. Negative correlations were found between $\mathrm{p}$-tau phosphorylation in the left and right anterior cortex, as well as the right hippocampus between move distance (left and right anterior cortex, right hippocampus), open arm time (right anterior cortex, right hippocampus) and cross arm latency (left and right anterior cortex, right hippocampus, Table 4). There were no significant correlations in left hippocampus, left or right amygdala as well as left or right posterior cortex (Table 4).

Similar correlations were seen in the left anterior cortex and right hippocampus in time spent and distance traveled on the light side of a light/dark escape task (Fig. 2 and Table 5), another test of anxiety, which is consistently affected in blast-exposed rats [81]. Changes were specific to $\mathrm{p}$-tau in that there were no consistent correlations between behavior in the elevated zero maze and total tau in regions where p-tau Thr181 correlated with behavior (Fig. 3 and Table 6). The only significant correlations were positive correlations between total tau in the left hippocampus with move distance and open arm time (Fig. 3c, e and Table 6).

Effects were specific to p-tau Thr181 in that no consistent correlations existed between behavioral parameters in the elevated zero maze (Fig. 4, Tables $7,8,9$ ) or light/ dark escape task (data not shown) with phosphorylation status at three other sites (threonine 231, serine 396, and serine 404) whose phosphorylation status was not changed following blast [21].

\section{P-Thr181 levels in the anterior neocortical regions and right hippocampus correlate with behavioral measures of fear learning and novel object localization in blast-exposed rats}

Besides anxiety blast-exposed rats exhibit a variety of other PTSD-related behavioral traits [78, 81]. Abnormal fear responses are a core feature of human PTSD and the rats under study here exhibited normal contextual fear learning but exaggerated cued responses suggestive of heightened amygdala activity [80]. There were no correlations between p-tau or total tau levels and 

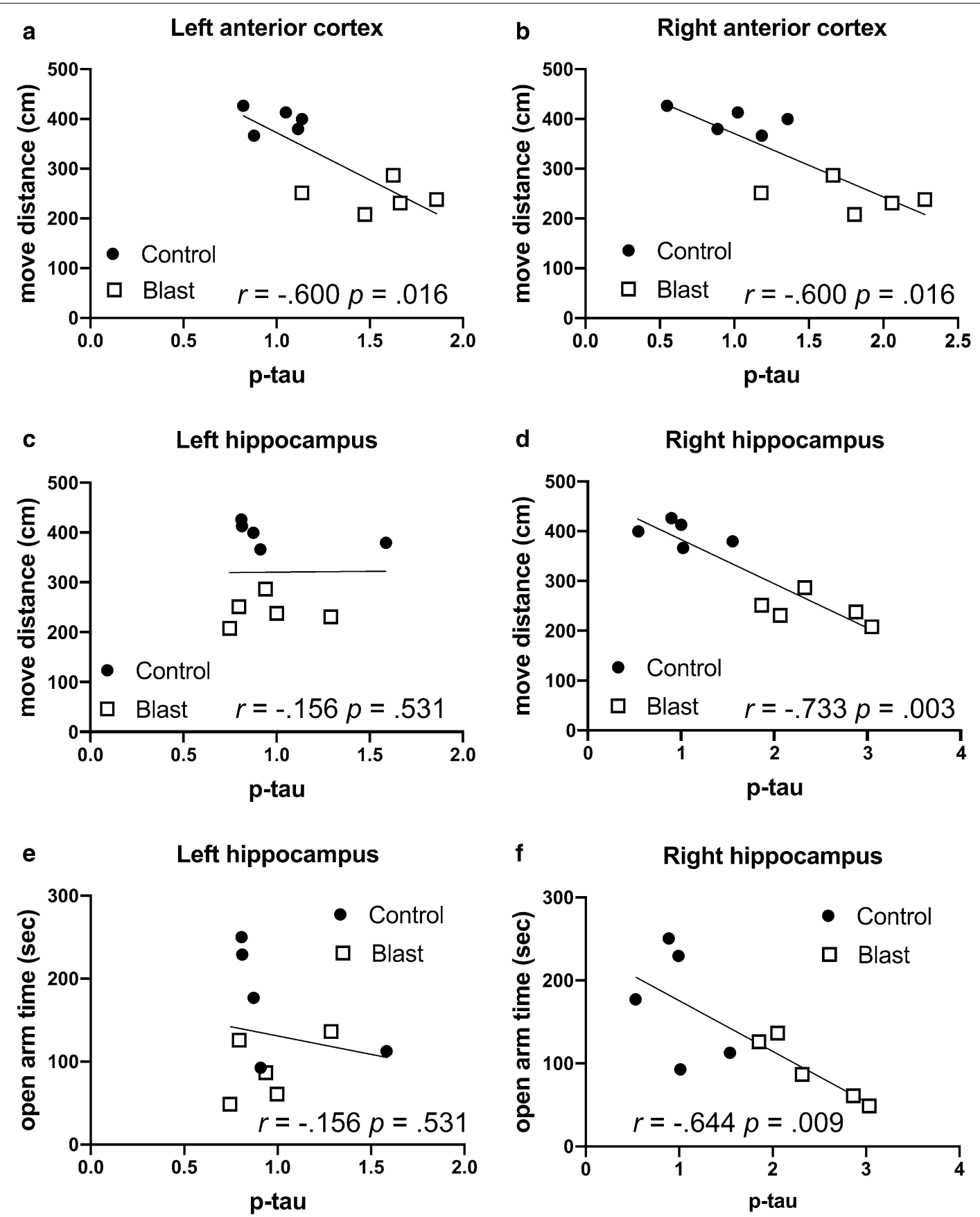

Fig. 1 Correlations between p-tau Thr181 in the anterior cortical regions and hippocampus with behavioral measures in the elevated zero maze. P-tau Thr181 levels were previously determined by Western blotting with the antibody AT270 [21] at 40 weeks after blast exposure and correlated with behavioral measures previously found affected in the elevated zero maze in the same blast-exposed rats at 30 weeks following blast exposure [80]. Distance traveled (move distance, a-d) and time spent in the open arms (open arm time, e, $\mathbf{f}$ ) are shown for the left anterior cortex (a), right anterior cortex (b), left hippocampus ( $\mathbf{c}, \mathbf{e})$ and right hippocampus (d, $\mathbf{f})$. Five blast and five control animals were analyzed. Kendall's tau-b correlation coefficients and $p$ values are indicated

total freezing during the 4 min of the contextual testing (data not shown), consistent with there being no differences between blast and control in this phase of the task as previously determined in these same animals [80]. By contrast in the cued phase comparing p-tau levels with freezing to the second tone showed positive correlations 
Table 4 Correlations between p-tau Thr181 levels and behavioral parameters in the elevated zero maze

\begin{tabular}{|c|c|c|c|c|c|c|}
\hline \multicolumn{7}{|l|}{ Elevated zero maze } \\
\hline \multirow[t]{2}{*}{ p-tau (Thr181) } & \multicolumn{2}{|l|}{ Pearson } & \multicolumn{2}{|c|}{ Kendall's tau-b } & \multicolumn{2}{|c|}{ Spearman's rho } \\
\hline & $\begin{array}{l}\text { Correlation } \\
\text { coefficient }\end{array}$ & $p$ value & $\begin{array}{l}\text { Correlation } \\
\text { coefficient }\end{array}$ & $p$ value & $\begin{array}{l}\text { Correlation } \\
\text { coefficient }\end{array}$ & $p$ value \\
\hline \multicolumn{7}{|l|}{ Left anterior cortex } \\
\hline Move distance & -.792 & .006 & -.600 & .016 & -.806 & .005 \\
\hline Open arm time & -.620 & .056 & -.422 & .089 & -.576 & .082 \\
\hline Cross arm latency & .624 & .054 & .556 & .025 & .782 & .008 \\
\hline \multicolumn{7}{|l|}{ Right anterior cortex } \\
\hline Move distance & -.814 & .004 & -.600 & .016 & -.806 & .005 \\
\hline Open arm time & -.676 & .032 & -.511 & .040 & -.624 & .054 \\
\hline Cross arm latency & .493 & .148 & .467 & .060 & .721 & .019 \\
\hline \multicolumn{7}{|l|}{ Left Hippocampus } \\
\hline Move distance & .010 & .979 & -.156 & .531 & -.055 & .881 \\
\hline Open arm time & -.173 & .633 & -.156 & .531 & -.115 & .751 \\
\hline Cross arm latency & -.033 & .928 & .022 & .929 & .042 & .907 \\
\hline \multicolumn{7}{|l|}{ Right Hippocampus } \\
\hline Move distance & -.901 & $<.001$ & -.733 & .003 & -.891 & .001 \\
\hline Open arm time & -.755 & .008 & -.644 & .009 & -.842 & .002 \\
\hline Cross arm latency & .564 & .090 & .689 & .006 & .879 & .001 \\
\hline \multicolumn{7}{|l|}{ Left Amygdala } \\
\hline Move distance & .120 & .741 & .156 & .531 & .248 & .489 \\
\hline Open arm time & .118 & .745 & -.022 & .929 & .042 & .907 \\
\hline Cross arm latency & .415 & .233 & -.111 & .655 & -.103 & .777 \\
\hline \multicolumn{7}{|l|}{ Right Amygdala } \\
\hline Move distance & -.016 & .966 & .111 & .655 & .127 & .726 \\
\hline Open arm time & .198 & .584 & .289 & .245 & .382 & .276 \\
\hline Cross arm latency & -.293 & .412 & -.244 & .325 & -.285 & .425 \\
\hline \multicolumn{7}{|l|}{ Left Posterior Cortex } \\
\hline Move distance & -.074 & .839 & .067 & .788 & .103 & .777 \\
\hline Open arm time & .057 & .877 & .156 & .531 & .055 & .881 \\
\hline Cross arm latency & .499 & .142 & .244 & .325 & .345 & .328 \\
\hline \multicolumn{7}{|l|}{ Right Posterior Cortex } \\
\hline Move distance & .199 & .581 & .111 & .655 & .224 & .533 \\
\hline Open arm time & .479 & .161 & .200 & .421 & .345 & .328 \\
\hline Cross arm latency & -.105 & .772 & -.067 & .788 & -.091 & .803 \\
\hline
\end{tabular}

P-tau Thr181 levels were previously determined by Western blotting with the antibody AT270 at 40 weeks after blast exposure [21] and correlated with three behavioral measures in the elevated zero maze (move distance, open arm time and cross arm latency) previously found to be affected in the same blast-exposed rats at 30 weeks following blast exposure [80]. Five blast and five control animals were analyzed. Correlations with $p$ values less than 0.05 are indicated in bold

between p-tau Thr181 levels and magnitude of freezing in the left and right anterior cortex (Fig. 5a, b and Table 10) but not the right hippocampus (Fig. 5c). When total tau levels were compared, only a single negative correlation was found between total tau and freezing in the right amygdala (Fig. 5d and Table 10).

Mild cognitive changes are a consistent feature of human PTSD [103]. The blast-exposed rats studied here previously showed normal recognition learning in a novel object recognition (NOR) task [78, 80]. In comparing p-tau levels to the NOR discrimination index (Table 11), a measure of the tendency of the animal to prefer the novel over the familiar object when recognition memory is tested later, there was only one positive correlation with p-tau Thr181 in the posterior cortex during the short-term memory (STM) testing conducted $2 \mathrm{~h}$ after the training session. However, this correlation was only found in Kendall's tau b, and was not replicated in Pearson's correlation coefficient or Spearman's rho (Table 11). In long-term memory (LTM) testing conducted $24 \mathrm{~h}$ after 

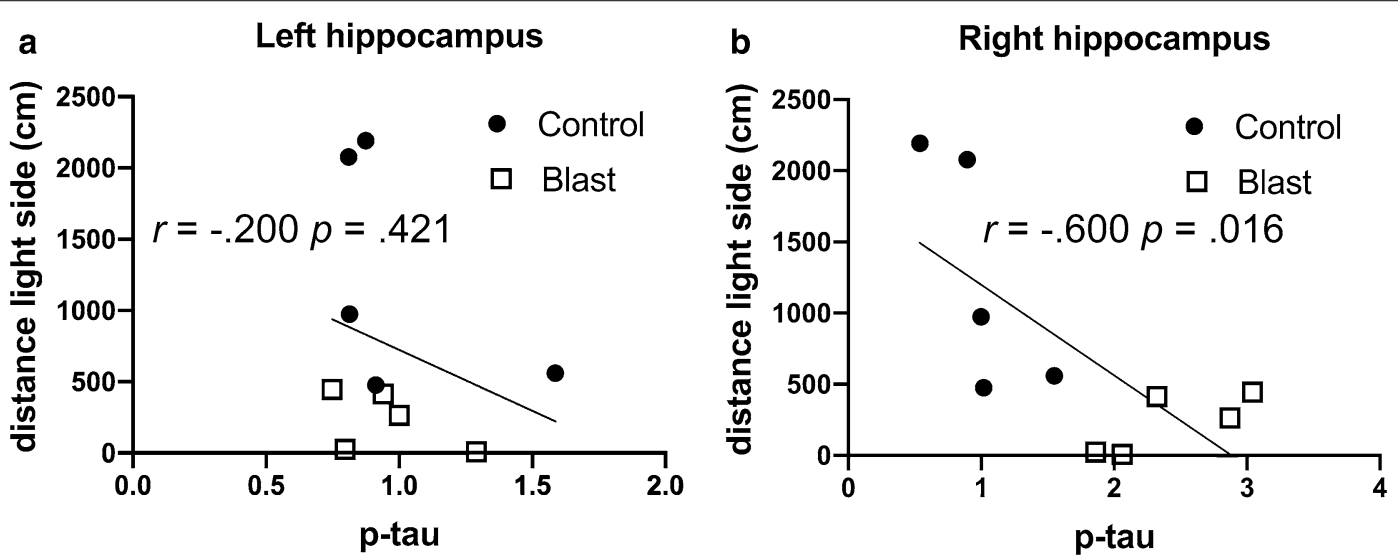

Fig. 2 Correlations between p-tau Thr181 levels and behavioral parameters in the light dark escape task. P-tau Thr181 levels [21] in the left (a) or right (b) hippocampus were determined at 40 weeks after blast exposure and correlated with total distance moved on the light side in the same animals tested at 29 weeks after blast exposure [80]. Five blast and five control animals were analyzed. Kendall's tau-b correlation coefficients and $p$ values are indicated

Table 5 Correlations between p-tau Thr181 levels and behavioral parameters in the light dark escape task

\begin{tabular}{|c|c|c|c|c|c|c|}
\hline \multicolumn{7}{|l|}{ Light dark escape } \\
\hline \multirow[t]{2}{*}{ p-tau (Thr181) } & \multicolumn{2}{|l|}{ Pearson } & \multicolumn{2}{|c|}{ Kendall's tau-b } & \multicolumn{2}{|c|}{ Spearman's rho } \\
\hline & $\begin{array}{l}\text { Correlation } \\
\text { coefficient }\end{array}$ & $p$ value & $\begin{array}{l}\text { Correlation } \\
\text { coefficient }\end{array}$ & $p$ value & $\begin{array}{l}\text { Correlation } \\
\text { coefficient }\end{array}$ & $p$ value \\
\hline \multicolumn{7}{|l|}{ Left anterior cortex } \\
\hline Total time light side & -.526 & .119 & -.511 & .040 & -.673 & .033 \\
\hline Total distance light side &.- .545 & .103 & -.556 & .025 & -.745 & .013 \\
\hline \multicolumn{7}{|l|}{ Right anterior cortex } \\
\hline Total time light side & -.474 & .166 & -.333 & .180 & -.467 & .174 \\
\hline Total distance light side & -.544 & .104 & -.467 & .060 & -.612 & .060 \\
\hline \multicolumn{7}{|l|}{ Left Hippocampus } \\
\hline Total time light side & -.447 & .195 & -.333 & .180 & -.430 & .214 \\
\hline Total distance light side & -.287 & .421 & -.200 & .421 & -.212 & .556 \\
\hline \multicolumn{7}{|l|}{ Right Hippocampus } \\
\hline Total time light side & -.633 & .050 & -.556 & .025 & -.648 & .043 \\
\hline Total distance light side & -.700 & .024 & -.600 & .016 & -.770 & .009 \\
\hline \multicolumn{7}{|l|}{ Left Amygdala } \\
\hline Total time light side & -.024 & .947 & -.022 & .929 & -.091 & .803 \\
\hline Total distance light side & .219 & .543 & .022 & .929 & -.018 & .960 \\
\hline \multicolumn{7}{|l|}{ Right Amygdala } \\
\hline Total time light side & -.026 & .944 & -.067 & .788 & -.139 & .701 \\
\hline Total distance light side & .144 & .691 & .067 & .788 & -.018 & .960 \\
\hline \multicolumn{7}{|l|}{ Left Posterior Cortex } \\
\hline Total time light side & .281 & .432 & .156 & .531 & .321 & .365 \\
\hline Total distance light side & .067 & .853 & .111 & .655 & .176 & .627 \\
\hline \multicolumn{7}{|l|}{ Right Posterior Cortex } \\
\hline Total time light side & .237 & .510 & .111 & .655 & .164 & .651 \\
\hline Total distance light side & .406 & .244 & .156 & .531 & .212 & .556 \\
\hline
\end{tabular}

P-tau Thr181 were measured for the same rats studied in Table 3 at 40 weeks after blast exposure [21] and correlated with total time on the light side or total distance moved on the light side in a light dark escape task tested at 29 weeks after blast exposure [80]. Five blast and five control animals were analyzed. Correlations with $p$ values equal to or less than 0.05 are indicated in bold 
Table 6 Correlations between total tau levels and behavioral parameters in the elevated zero maze

\begin{tabular}{|c|c|c|c|c|c|c|}
\hline \multicolumn{7}{|c|}{ Elevated zero maze } \\
\hline \multirow[t]{2}{*}{ Total tau } & \multicolumn{2}{|l|}{ Pearson } & \multicolumn{2}{|c|}{ Kendall's tau-b } & \multicolumn{2}{|c|}{ Spearman's rho } \\
\hline & $\begin{array}{l}\text { Correlation } \\
\text { coefficient }\end{array}$ & $p$ value & $\begin{array}{l}\text { Correlation } \\
\text { coefficient }\end{array}$ & $p$ value & $\begin{array}{l}\text { Correlation } \\
\text { coefficient }\end{array}$ & $p$ value \\
\hline \multicolumn{7}{|l|}{ Left anterior cortex } \\
\hline Move distance & -.057 & .875 & -.067 & .788 & .018 & .960 \\
\hline Open arm time & .040 & .913 & .022 & .929 & .127 & .726 \\
\hline Cross arm latency & .230 & .522 & .022 & .929 & .055 & .881 \\
\hline \multicolumn{7}{|l|}{ Right anterior cortex } \\
\hline Move distance & -.396 & .257 & -.333 & .180 & -.455 & .187 \\
\hline Open arm time & -.390 & .265 & -.244 & .325 & -.370 & .293 \\
\hline Cross arm latency & -.114 & .753 & .289 & .245 & .358 & .310 \\
\hline \multicolumn{7}{|l|}{ Left Hippocampus } \\
\hline Move distance & .508 & .134 & .600 & .016 & .770 & .009 \\
\hline Open arm time & .696 & .025 & .511 & .040 & .697 & .025 \\
\hline Cross arm latency & .076 & .834 & -.289 & .245 & -.394 & .260 \\
\hline \multicolumn{7}{|l|}{ Right Hippocampus } \\
\hline Move distance & .550 & .100 & .467 & .060 & .588 & .074 \\
\hline Open arm time & .526 & .119 & .378 & .128 & .503 & .138 \\
\hline Cross arm latency & .261 & .467 & -.156 & .531 & -.152 & .676 \\
\hline \multicolumn{7}{|l|}{ Left Amygdala } \\
\hline Move distance & .158 & .662 & .022 & .929 & .018 & .960 \\
\hline Open arm time & .189 & .601 & .111 & .655 & .152 & .676 \\
\hline Cross arm latency & -.559 & .093 & -.244 & .325 & -.297 & .405 \\
\hline \multicolumn{7}{|l|}{ Right Amygdala } \\
\hline Move distance & .278 & .437 & .244 & .325 & .382 & .276 \\
\hline Open arm time & -.048 & .894 & -.022 & .929 & .018 & .960 \\
\hline Cross arm latency & .361 & .306 & -.111 & .655 & -.115 & .751 \\
\hline \multicolumn{7}{|l|}{ Left Posterior Cortex } \\
\hline Move distance & .361 & .305 & .333 & .180 & .345 & .328 \\
\hline Open arm time & .080 & .826 & .067 & .788 & .127 & .726 \\
\hline Cross arm latency & -.272 & .448 & -.378 & .128 & -.455 & .187 \\
\hline \multicolumn{7}{|l|}{ Right Posterior Cortex } \\
\hline Move distance & -.629 & .051 & -.511 & .040 & -.697 & .025 \\
\hline Open arm time & -.489 & .151 & -.244 & .325 & -.382 & .276 \\
\hline Cross arm latency & -.126 & .729 & .200 & .421 & .236 & .511 \\
\hline
\end{tabular}

Total tau levels were previously determined by Western blotting at 40 weeks after blast exposure [21]. Total tau levels were correlated with three behavioral parameters in the elevated zero maze (move distance, open arm time and cross arm latency) previously found to be affected in blast-exposed animals at 30 weeks following blast exposure [80]. Five blast and five control animals were analyzed. Correlations with $p$ values less than 0.05 are indicated in bold

the training session, no correlations were found with p-tau in any region (data not shown). There were also no correlations between total tau and the discrimination index in either STM (Table 11) or LTM testing (data not shown) in the NOR. The paucity of correlations is consistent with there being no impairment in NOR learning in this cohort of blast-exposed rats [80].

By contrast these same blast-exposed rats were impaired in recognition memory in a novel object localization (NOL) task [80]. In NOL testing there were negative correlations in left anterior cortex, right anterior cortex and right hippocampus between p-tau Thr181 levels and the discrimination index (Fig. 6 and Table 12). There were only isolated positive or negative correlations of total tau with the discrimination index in the left hippocampus and right posterior cortex that were not replicated across all three correlation coefficients (Table 12). 
Table 7 Correlations between p-tau Thr231 levels and behavioral parameters in the elevated zero maze

\begin{tabular}{|c|c|c|c|c|c|c|}
\hline \multicolumn{7}{|c|}{ Elevated zero maze } \\
\hline \multirow[t]{2}{*}{ p-tau Thr231 } & \multicolumn{2}{|l|}{ Pearson } & \multicolumn{2}{|c|}{ Kendall's tau-b } & \multicolumn{2}{|c|}{ Spearman's rho } \\
\hline & $\begin{array}{l}\text { Correlation } \\
\text { coefficient }\end{array}$ & $p$ value & $\begin{array}{l}\text { Correlation } \\
\text { coefficient }\end{array}$ & $p$ value & $\begin{array}{l}\text { Correlation } \\
\text { coefficient }\end{array}$ & $p$ value \\
\hline \multicolumn{7}{|l|}{ Left anterior cortex } \\
\hline Move distance & -.373 & .288 & -.244 & .325 & -.309 & .385 \\
\hline Open arm time & -.540 & .107 & -.333 & .180 & -.455 & .187 \\
\hline Cross arm latency & .087 & .811 & .022 & .929 & .018 & .960 \\
\hline \multicolumn{7}{|l|}{ Right anterior cortex } \\
\hline Move distance & .139 & .702 & -.067 & .788 & -.139 & .701 \\
\hline Open arm time & -.146 & .687 & -.156 & .531 & -.297 & .405 \\
\hline Cross arm latency & -.059 & .871 & .022 & .929 & -.006 & .987 \\
\hline \multicolumn{7}{|l|}{ Left Hippocampus } \\
\hline Move distance & .057 & .876 & .111 & .655 & .139 & .701 \\
\hline Open arm time & -.305 & .392 & -.244 & .325 & -.285 & .425 \\
\hline Cross arm latency & .396 & .257 & .022 & .929 & .055 & .881 \\
\hline \multicolumn{7}{|l|}{ Right Hippocampus } \\
\hline Move distance & .455 & .186 & .333 & .180 & .442 & .200 \\
\hline Open arm time & .489 & .151 & .422 & .089 & .552 & .098 \\
\hline Cross arm latency & -.158 & .662 & -.200 & .421 & -.285 & .425 \\
\hline
\end{tabular}

P-tau Thr231 levels were previously determined by Western blotting at 40 weeks after blast exposure [21]. P-tau Thr231 levels were correlated with three behavioral parameters in the elevated zero maze (move distance, open arm time and cross arm latency) determined at 30 weeks following blast exposure [80]. Five blast and five control animals were analyzed. No values were statistically significant

\section{P-tau Thr 181 levels do not correlate with behavioral measures of hyperarousal in blast-exposed rats}

Hyperarousal is a core feature of PTSD [103] and acoustic startle response is increased in humans with PTSD [12, 72, 77]. When control and blast-exposed animals were previously examined in an acoustic startle/prepulse inhibition (PPI) paradigm, while there were no overall group differences in response to acoustic startle, blast-exposed rats exhibited an increased percentage PPI and showed a larger differential when the response following a prepulse was subtracted from the acoustic startle [80]. However, no correlations were found between p-tau Thr181 levels and the percentage PPI or when the prepulse response was subtracted from the acoustic startle (Table 13).

\section{Discussion}

While symptoms following mTBI frequently resolve, many veterans' complaints persist and evolve into a chronic postconcussion syndrome that can last for years. Besides static symptoms, new complaints may also develop [53, 64]. In a longitudinal study of US military personnel who suffered blast-related TBIs in Afghanistan, with 1 and 5 years of follow-up times, overall global functioning declined in over $70 \%$, declines nearly completely driven by worsening PTSD and depression [64]. The degree to which this worsening is driven by blast-related mechanisms vs. purely mental health-related factors is unclear.

This study utilized an animal model that was designed to mimic a blast-related human mild TBI or subclinical blast exposure. Studies using this system established that exposures up to $74.5 \mathrm{kPa}$ (equivalent to $10.8 \mathrm{psi}$ ), while representing a level of blast that is transmitted to brain [16] produce no gross neuropathological effects, and histological examination of the lung shows no hemorrhage or other pathology [1]. Because blast-related TBI may involve a combination of injuries related to effects of the primary blast wave as well as damage from rotational/ acceleration injury $[15,92]$, during the blast overpressure exposures head motion is restricted to minimize rotation/acceleration injury. The lack of evidence for coup/ contrecoup injuries or brain tissue damage generally on histology supports the mild nature of the injury and the lack of significant rotation/acceleration injury $[1,26]$. Because multiple blast exposures were common among veterans returning from Iraq and Afghanistan [28], in most experiments (including the present) we have used a design in which rats received three $74.5-\mathrm{kPa}$ exposures delivered one exposure per day on 3 consecutive days.

Altered tau processing has frequently been observed in experimental animal models of blast injury $[2,4,5,11$, 


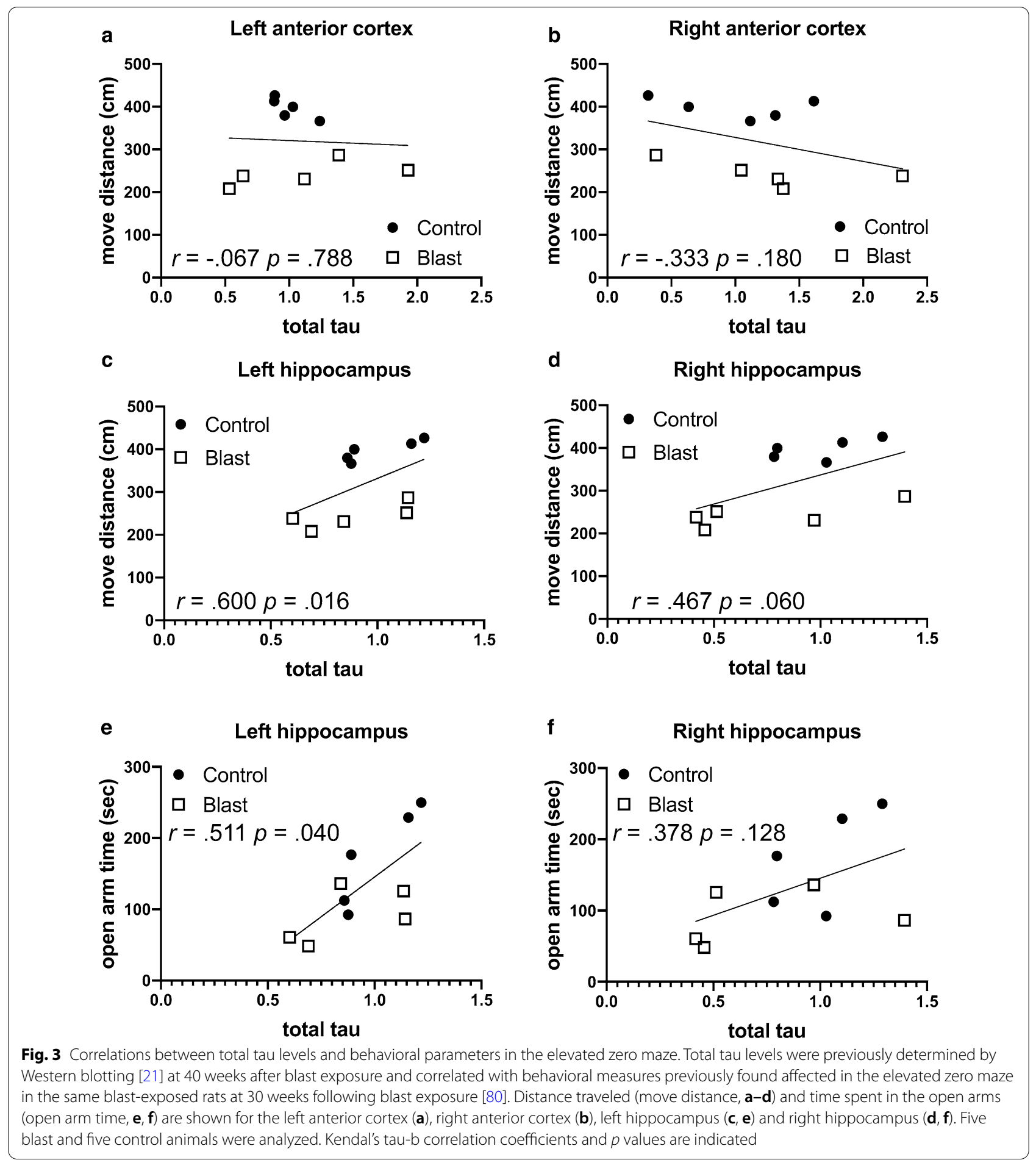

$13,17,22,23,35,39,43,44,52,57,58,61-63,67,70,73$, 83, 86, 88]. The blast-exposed rats studied here develop a variety of chronic and persistent PTSD-related behavioral traits [81] following repetitive low-level blast exposure. They also accumulate abnormal levels of p-tau in a region-specific pattern [21].

Here, we compared region-specific patterns of tau phosphorylation with previous behavioral testing performed on the same rats [80] using data sets that were 


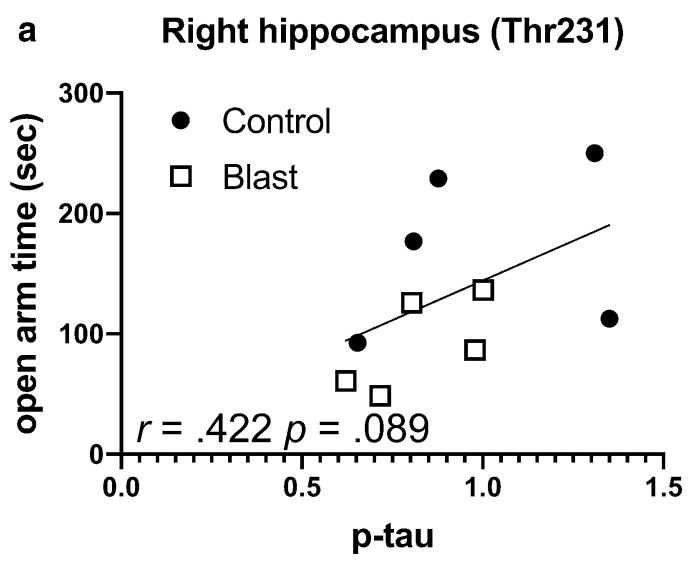

b Right hippocampus (Ser396)

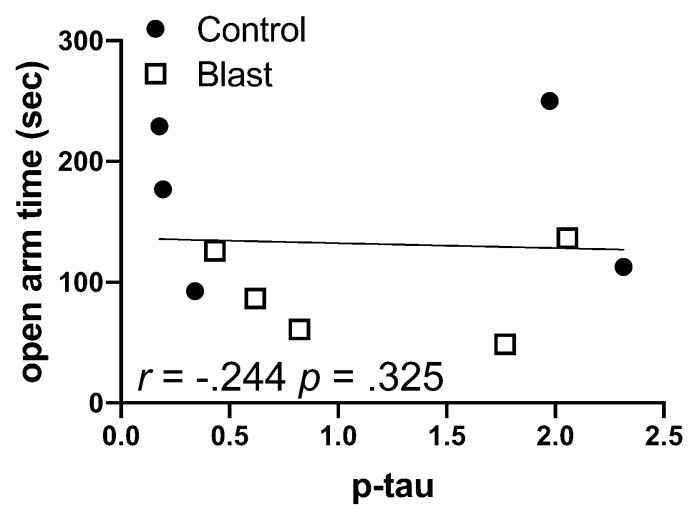

C Right hippocampus (Ser404)

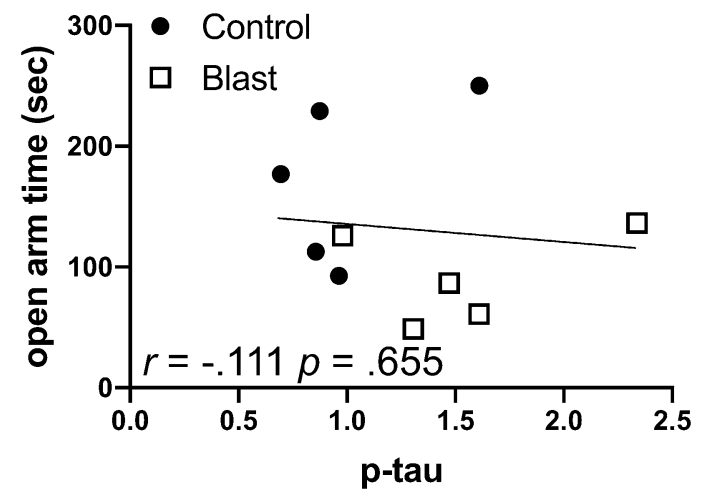

Fig. 4 Correlations between levels of p-tau Thr231, Ser396 and Ser404 with open arm time in the elevated zero maze. Levels of $p$-tau Thr231 (a), Ser396 (b) and Ser404 (c) in the right hippocampus were previously determined by Western blotting [21] at 40 weeks after blast exposure and correlated with open arm time in the elevated zero maze determined at 30 weeks following blast exposure [80]. Five blast and five control animals were analyzed. Kendal's tau-b correlation coefficients and $p$ values are indicated published in prior studies $[21,80]$. The results are summarized in Table 14. The most consistent correlations were with p-tau levels in the left anterior cortex, right anterior cortex and right hippocampus, regions in which p-tau was elevated (Table 3). In these regions, p-tau levels correlated negatively with measures of anxiety in an elevated zero maze and a light/dark escape task as well as object localization memory in an NOL task while they correlated positively with freezing in the cued phase of a fear-conditioning paradigm. All these correlations are consistent with evidence of anxiety, impaired NOL learning and exaggerated fear responses in blast-exposed rats [80]. Only isolated positive or negative correlations were found between total tau in the left hippocampus and measures of anxiety or fear learning (Table 14).

A limitation of these studies is the relatively modest sample size of animals for which both behavioral and quantitative tau phosphorylation data were available. There are also challenges with statistical testing of relatively small sample sizes. While most data sets did not violate normality (data not shown) we calculated both parametric (Pearson's product moment) and non-parametric (Kendall's tau-b and Spearman's rho) correlation tests. Agreement between the three tests was generally high with only a few instances in which Kendall's tau-b and/or Spearman's rho yielded significant correlations while Pearson's did not. Kendall's tau-b is generally considered to give better estimates of the population value with small data sets or when data has failed one or more assumptions [32, 42]. For those reasons Kendall's tau-b is presented in figures. It remains possible that an increased sample size would identify more statistically significant correlations.

The rat model under study here also develops pathological accumulation of hyperphosphorylated tau in neuronal perikarya and perivascular astroglial processes in multiple brain regions [21]. In future studies it will be interesting to explore the relationship of these accumulations with behavioral measures as well as whether the degenerative pathology spreads in a manner comparable to that observed in a variety of human neurodegenerative diseases [24]. Several groups including our own have observed retention of the PET tau ligand $\left[{ }^{18} \mathrm{~F}\right]$ AV1451 (flortaucipir) in military veterans who suffered from chronic cognitive and neurobehavioral syndromes after blast injury [21, 71, 84]. It may be possible to better understand the laterality and spread of disease using similar ligands in rats. 
Table 8 Correlations between p-tau Ser396 levels and behavioral parameters in the elevated zero maze

\begin{tabular}{|c|c|c|c|c|c|c|}
\hline \multicolumn{7}{|l|}{ Elevated zero maze } \\
\hline \multirow[t]{2}{*}{ p-tau Ser396 } & \multicolumn{2}{|l|}{ Pearson } & \multicolumn{2}{|c|}{ Kendall's tau-b } & \multicolumn{2}{|c|}{ Spearman's rho } \\
\hline & $\begin{array}{l}\text { Correlation } \\
\text { coefficient }\end{array}$ & $p$ value & $\begin{array}{l}\text { Correlation } \\
\text { coefficient }\end{array}$ & $p$ value & $\begin{array}{l}\text { Correlation } \\
\text { coefficient }\end{array}$ & $p$ value \\
\hline \multicolumn{7}{|l|}{ Left anterior cortex } \\
\hline Move distance & -.632 & .050 & -.467 & .060 & -.612 & .060 \\
\hline Open arm time & -.473 & .167 & -.378 & .128 & -.491 & .150 \\
\hline Cross arm latency & .125 & .732 & .333 & .180 & .418 & .229 \\
\hline \multicolumn{7}{|l|}{ Right anterior cortex } \\
\hline Move distance & -.563 & .090 & -.422 & .089 & -.636 & .048 \\
\hline Open arm time & -.331 & .350 & -.333 & .180 & -.455 & .187 \\
\hline Cross arm latency & .229 & .524 & .289 & .245 & .491 & .150 \\
\hline \multicolumn{7}{|l|}{ Left Hippocampus } \\
\hline Move distance & -.360 & .307 & -.244 & .325 & -.382 & .276 \\
\hline Open arm time & -.314 & .377 & -.244 & .325 & -.333 & .347 \\
\hline Cross arm latency & .535 & .111 & .289 & .245 & .442 & .200 \\
\hline \multicolumn{7}{|l|}{ Right Hippocampus } \\
\hline Move distance & -.157 & .665 & -.333 & .180 & -.309 & .385 \\
\hline Open arm time & -.051 & .888 & -.244 & .325 & -.176 & .627 \\
\hline Cross arm latency & -.165 & .649 & .111 & .655 & .091 & .803 \\
\hline
\end{tabular}

P-tau Ser396 levels were previously determined by Western blotting at 40 weeks after blast exposure [21]. P-tau Ser396 levels were correlated with three behavioral parameters in the elevated zero maze (move distance, open arm time and cross arm latency) determined at 30 weeks following blast exposure [80]. Five blast and five control animals were analyzed. Correlations with $p$ values less than 0.05 are indicated in bold

Table 9 Correlations between p-tau Ser404 levels and behavioral parameters in the elevated zero maze

\begin{tabular}{|c|c|c|c|c|c|c|}
\hline \multicolumn{7}{|l|}{ Elevated zero maze } \\
\hline \multirow[t]{2}{*}{ p-tau Ser404 } & \multicolumn{2}{|l|}{ Pearson } & \multicolumn{2}{|c|}{ Kendall's tau-b } & \multicolumn{2}{|c|}{ Spearman's rho } \\
\hline & $\begin{array}{l}\text { Correlation } \\
\text { coefficient }\end{array}$ & $p$ value & $\begin{array}{l}\text { Correlation } \\
\text { coefficient }\end{array}$ & $p$ value & $\begin{array}{l}\text { Correlation } \\
\text { coefficient }\end{array}$ & $p$ value \\
\hline \multicolumn{7}{|l|}{ Left anterior cortex } \\
\hline Move distance & -.482 & .158 & -.244 & .325 & -.382 & .276 \\
\hline Open arm time & -.219 & .543 & -.067 & .788 & -.176 & .627 \\
\hline Cross arm latency & .468 & .172 & .467 & .060 & .648 & .043 \\
\hline \multicolumn{7}{|l|}{ Right anterior cortex } \\
\hline Move distance & -.495 & .146 & -.378 & .128 & -.539 & .108 \\
\hline Open arm time & -.481 & .159 & -.378 & .128 & -.552 & .098 \\
\hline Cross arm latency & .219 & .544 & .333 & .180 & .564 & .090 \\
\hline \multicolumn{7}{|l|}{ Left Hippocampus } \\
\hline Move distance & -.309 & .385 & -.244 & .325 & -.358 & .310 \\
\hline Open arm time & -.280 & .434 & -.156 & .531 & -.248 & .489 \\
\hline Cross arm latency & .299 & .402 & .111 & .655 & .285 & .425 \\
\hline \multicolumn{7}{|l|}{ Right Hippocampus } \\
\hline Move distance & -.520 & .123 & -.378 & .128 & -.418 & .229 \\
\hline Open arm time & -.110 & .762 & -.111 & .655 & -.103 & .777 \\
\hline Cross arm latency & .294 & .409 & .422 & .089 & .430 & .214 \\
\hline
\end{tabular}

P-tau Ser404 levels were previously determined by Western blotting at 40 weeks after blast exposure [21]. P-tau Ser404 levels were correlated with three behavioral parameters in the elevated zero maze (move distance, open arm time and cross arm latency) determined at 30 weeks following blast exposure [80]. Five blast and five control animals were analyzed. Correlations with $p$ values less than 0.05 are indicated in bold 


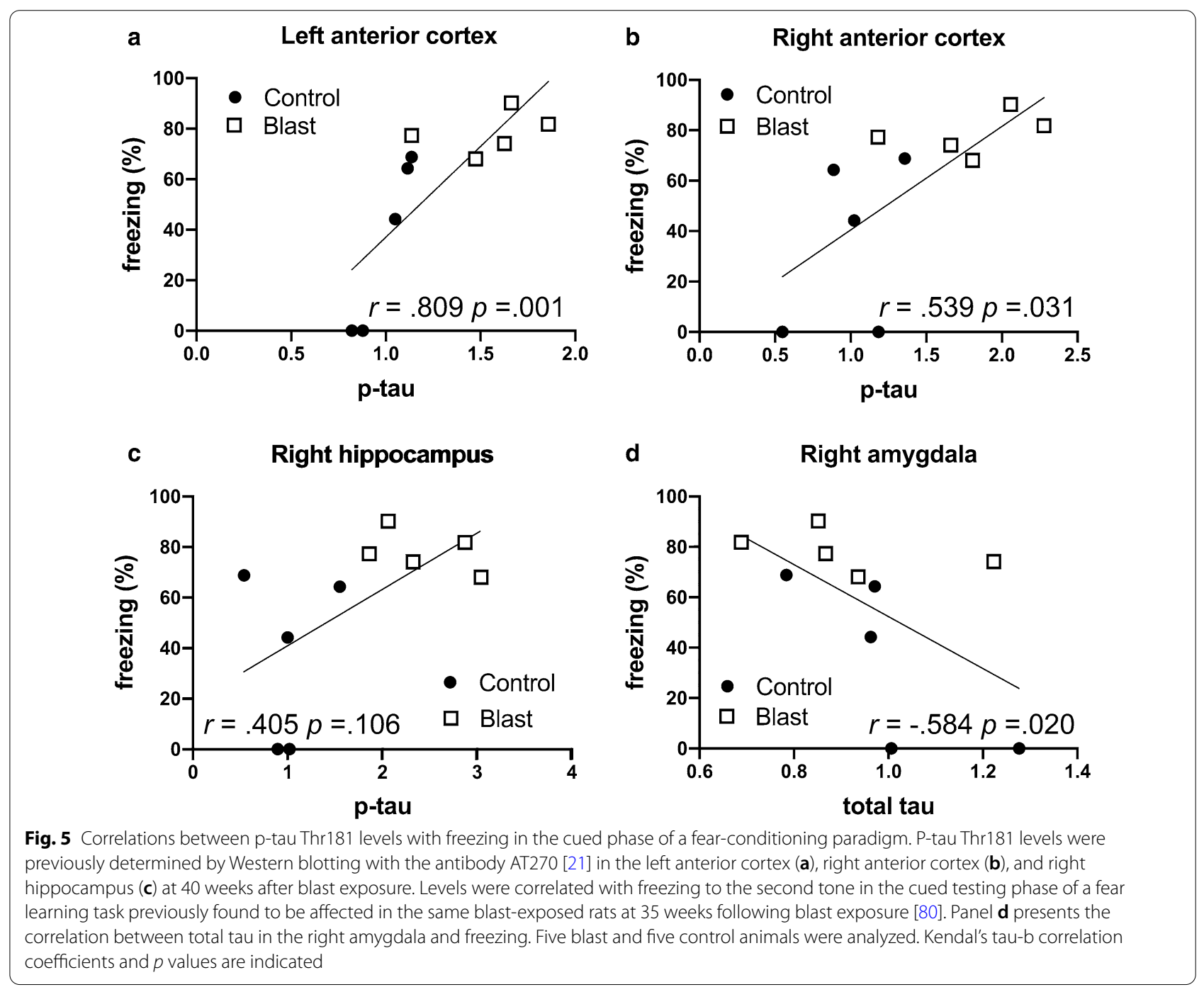

These studies also suggest tau accumulations as a possible therapeutic target following blast injury. Studies in mice have suggested that tau KO mice are resistant to stress-induced behavioral changes and hippocampal pathology [60]. Whether knocking down tau on a regional basis could reverse blast-induced behavioral changes could be tested in rats. The microtubule stabilizing agent epothilone $\mathrm{D}$ has been shown to reduce pathological aggregation and phosphorylation of tau and lead to improvements in behavioral function in transgenic mouse models of human tauopathies [7, $10,109]$. It would of great translational relevance to test whether microtubule stabilizing agents such epothilone $\mathrm{D}$ can reverse the chronic behavioral effects that follow blast injury in rats.

Current biological models of PTSD hold that specific brain regions, including the prefrontal cortex, amygdala, and hippocampus, are involved in its development $[55,56,66]$. These models suggest that a key component of the disorder is inadequate frontal inhibition of the amygdala, a structure central to fear responses and formation of fear associations [55, 56]. Exaggerated amygdala responses are thought to heighten responses to psychological threats. Functional neuroimaging data in humans are consistent with such models, suggesting that heightened amygdala activity is associated with decreased hippocampal and orbitofrontal activity in PTSD [56]. These areas strongly overlap with brain areas known to support fear learning in rodents $[81,100]$.

A number of our observations are consistent with such models and with p-tau playing a role in their molecular basis (Fig. 7). There were strong positive correlations between freezing behavior in the cued phase of a fear 
Table 10 Correlations between p-tau Thr181 and total tau levels with freezing in the cued phase of a fear-conditioning paradigm

\begin{tabular}{|c|c|c|c|c|c|c|}
\hline \multicolumn{7}{|l|}{ Cued Fear (freezing) } \\
\hline \multirow[b]{2}{*}{ p-tau (Thr181) vs. freezing } & \multicolumn{2}{|l|}{ Pearson } & \multicolumn{2}{|c|}{ Kendall's tau-b } & \multicolumn{2}{|c|}{ Spearman's rho } \\
\hline & $\begin{array}{l}\text { Correlation } \\
\text { coefficient }\end{array}$ & $p$ value & $\begin{array}{l}\text { Correlation } \\
\text { coefficient }\end{array}$ & $p$ value & $\begin{array}{l}\text { Correlation } \\
\text { coefficient }\end{array}$ & $p$ value \\
\hline Left anterior cortex & .789 & .007 & .809 & .001 & .924 & $<0.001$ \\
\hline Right anterior cortex & .692 & .031 & .539 & .031 & .736 & .015 \\
\hline Left Hippocampus & .296 & .406 & .270 & .281 & .304 & .393 \\
\hline Right Hippocampus & .593 & .071 & .405 & .106 & .565 & .089 \\
\hline Left Amygdala & -.052 & .887 & .090 & .719 & .116 & .751 \\
\hline Right Amygdala & .323 & .363 & .315 & .209 & .438 & .206 \\
\hline Left Posterior Cortex & .095 & .795 & .000 & 1.000 & -.018 & .960 \\
\hline Right Posterior Cortex & -.211 & .553 & .045 & .857 & -.030 & .934 \\
\hline \multicolumn{7}{|l|}{ Total tau vs. freezing } \\
\hline Left anterior cortex & .085 & .816 & .180 & .472 & .201 & .578 \\
\hline Right anterior cortex & .347 & .326 & .180 & .472 & .261 & .466 \\
\hline Left Hippocampus & -.376 & .284 & -.360 & .151 & -.486 & .154 \\
\hline Right Hippocampus & -.484 & .157 & -.315 & .209 & -.432 & .213 \\
\hline Left Amygdala & -.017 & .963 & -.135 & .590 & -.243 & .498 \\
\hline Right Amygdala & -.581 & .078 & -.584 & .020 & -.711 & .021 \\
\hline Left Posterior Cortex & -.243 & .500 & -.180 & .472 & -.316 & .374 \\
\hline Right Posterior Cortex & .393 & .262 & .360 & .151 & .523 & .121 \\
\hline
\end{tabular}

P-tau Thr181 and total tau levels were previously determined by Western blotting with the antibody AT270 at 40 weeks after blast exposure [21]. P-tau levels were correlated with freezing to the second tone in the cued testing phase of a fear learning task previously found to be affected in the same blast-exposed rats at 35 weeks following blast exposure [80]. Five blast and five control animals were analyzed. Correlations with $p$ values less than 0.05 are indicated in bold

Table 11 Correlations between p-tau Thr181 and total tau levels with the discrimination index in a novel object recognition task Novel object recognition (short-term memory)

\begin{tabular}{|c|c|c|c|c|c|c|}
\hline \multirow{2}{*}{$\begin{array}{l}\text { p-tau (Thr181) vs. } \\
\text { discrimination index }\end{array}$} & \multicolumn{2}{|l|}{ Pearson } & \multicolumn{2}{|c|}{ Kendall's tau-b } & \multicolumn{2}{|c|}{ Spearman's rho } \\
\hline & $\begin{array}{l}\text { Correlation } \\
\text { coefficient }\end{array}$ & $p$ value & $\begin{array}{l}\text { Correlation } \\
\text { coefficient }\end{array}$ & $p$ value & $\begin{array}{l}\text { Correlation } \\
\text { coefficient }\end{array}$ & $p$ value \\
\hline Left anterior cortex & -.132 & .716 & -.156 & .531 & -.176 & .627 \\
\hline Right anterior cortex & -.373 & .289 & -.244 & .325 & -.382 & .276 \\
\hline Left Hippocampus & .049 & .893 & -.067 & .788 & -.055 & .881 \\
\hline Right Hippocampus & -.026 & .943 & .067 & .788 & -.006 & .987 \\
\hline Left Amygdala & -.015 & .967 & -.022 & .929 & -.224 & .533 \\
\hline Right Amygdala & -.149 & .680 & -.156 & .531 & -.176 & .627 \\
\hline Left Posterior Cortex & .545 & .104 & .511 & .040 & .527 & .117 \\
\hline Right Posterior Cortex & .035 & .924 & .200 & .421 & .297 & .405 \\
\hline \multicolumn{7}{|c|}{ Total tau vs. discrimination index } \\
\hline Left anterior cortex & -.330 & .352 & -.333 & .180 & -.491 & .150 \\
\hline Right anterior cortex & -.137 & .706 & .022 & .929 & .103 & .777 \\
\hline Left Hippocampus & .205 & .570 & .156 & .531 & .200 & .580 \\
\hline Right Hippocampus & .052 & .886 & .022 & .929 & .079 & .829 \\
\hline Left Amygdala & .337 & .340 & .289 & .245 & .382 & .276 \\
\hline Right Amygdala & -.042 & .908 & .156 & .531 & .176 & .627 \\
\hline Left Posterior Cortex & .227 & .529 & -.111 & .655 & -.091 & .803 \\
\hline Right Posterior Cortex & -.364 & .300 & -.333 & .180 & -.479 & .162 \\
\hline
\end{tabular}

P-tau Thr181 levels were previously determined by Western blotting with the antibody AT270 at 40 weeks after blast exposure [21]. P-tau levels were correlated with the discrimination index in a novel object recognition task previously found to be affected in the same blast-exposed rats at 33 weeks following blast exposure [80]. Five blast and five control animals were analyzed. Correlations with $p$ values less than 0.05 are indicated in bold 

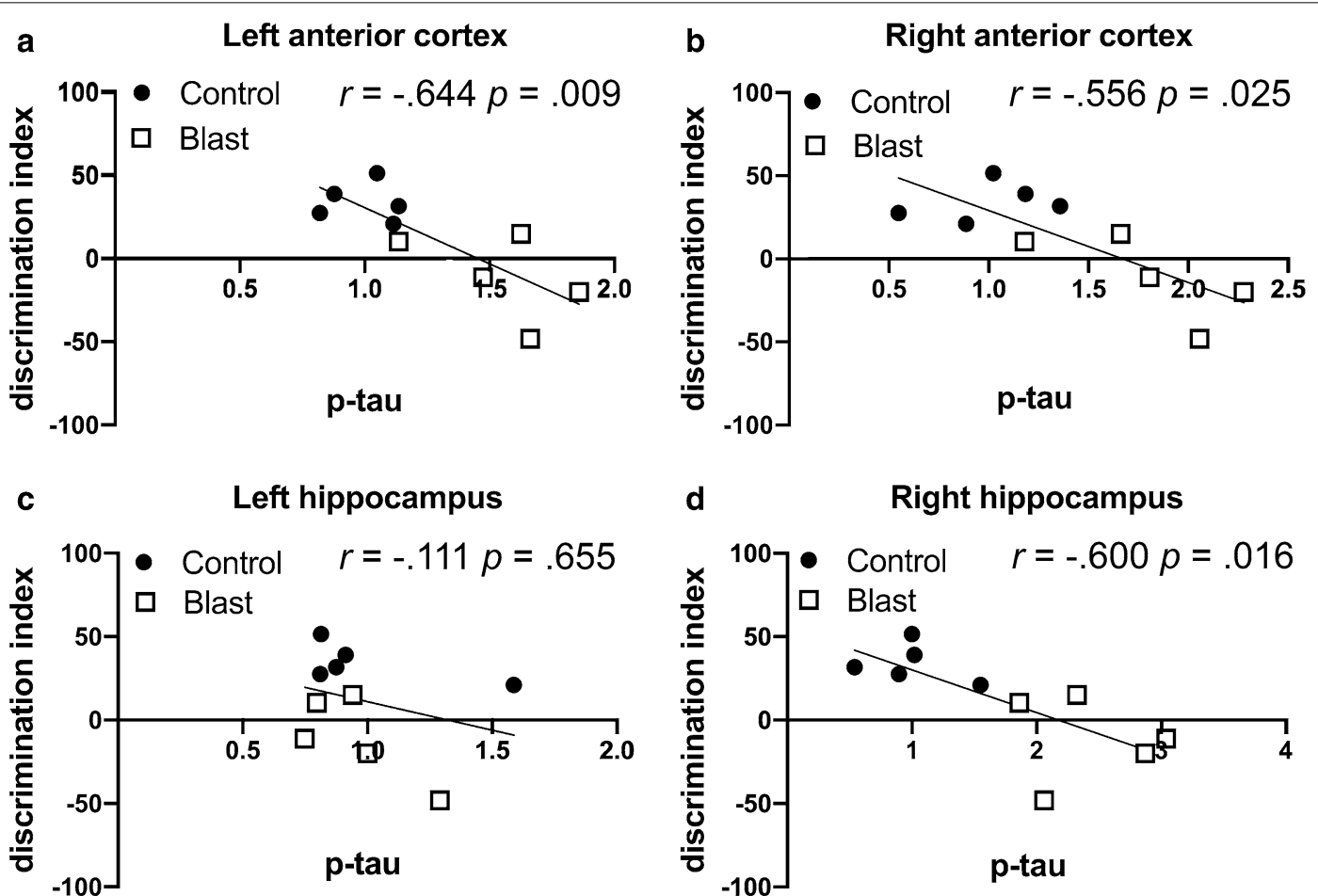

Fig. 6 Correlations between p-tau Thr181 levels with the discrimination index in a novel object localization task. P-tau Thr181 levels were previously determined by Western blotting with the antibody AT270 [21] in the left anterior cortex (a), right anterior cortex (b), left hippocampus (c) and right hippocampus (d) at 40 weeks after blast exposure. Levels were correlated with the discrimination index in a novel object localization task previously found affected in the same blast-exposed rats at 33 weeks following exposure [80]. Five blast and five control animals were analyzed. Kendal's tau-b correlation coefficients and $p$ values are indicated

Table 12 Correlations between p-tau Thr181 and total tau levels with the discrimination index in a novel object localization task

\begin{tabular}{|c|c|c|c|c|c|c|}
\hline \multicolumn{7}{|c|}{ Novel object localization (discrimination index) } \\
\hline \multirow[t]{2}{*}{ p-tau (Thr181) } & \multicolumn{2}{|l|}{ Pearson } & \multicolumn{2}{|l|}{ Kendall's tau-b } & \multicolumn{2}{|l|}{ Spearman's rho } \\
\hline & Correlation coefficient & $p$ value & Correlation coefficient & $p$ value & Correlation coefficient & $p$ value \\
\hline Left anterior cortex & -.791 & .006 & -.644 & .009 & -.842 & .002 \\
\hline Right anterior cortex & -.781 & .008 & -.556 & .025 & -.685 & .029 \\
\hline Left Hippocampus & -.299 & .402 & -.111 & .655 & -.200 & .580 \\
\hline Right Hippocampus & -.732 & .016 & -.600 & .016 & -.794 & .006 \\
\hline Left Amygdala & .110 & .762 & -.067 & .788 & -.030 & .934 \\
\hline Right Amygdala & -.377 & .283 & -.111 & .655 & -.273 & .446 \\
\hline Left Posterior Cortex & .136 & .707 & .022 & .929 & .055 & .881 \\
\hline Right Posterior Cortex & -.238 & .509 & -.111 & .655 & -.127 & .726 \\
\hline \multicolumn{7}{|c|}{ Total tau vs. discrimination index } \\
\hline Left anterior cortex & .142 & .696 & -.022 & .929 & .055 & .881 \\
\hline Right anterior cortex & -.367 & .296 & .200 & .421 & -.285 & .425 \\
\hline Left Hippocampus & .562 & .091 & .467 & .060 & .648 & .043 \\
\hline Right Hippocampus & .409 & .240 & .422 & .089 & .527 & .117 \\
\hline Left Amygdala & -.142 & .695 & -.111 & .655 & -.111 & -.067 \\
\hline Right Amygdala & .462 & .179 & .378 & .128 & .515 & .128 \\
\hline Left Posterior Cortex & .151 & .677 & .111 & .655 & .127 & .726 \\
\hline Right Posterior Cortex & -.704 & .023 & -.467 & .060 & -.673 & .033 \\
\hline
\end{tabular}

P-tau Thr181 levels were previously determined by Western blotting with the antibody AT270 at 40 weeks after blast exposure. [21]. P-tau levels were correlated with the discrimination index in a novel object localization task previously found to be affected in the same blast-exposed rats at 33 weeks following blast exposure [80]. Five blast and five control animals were analyzed. Correlations with $p$ values less than 0.05 are indicated in bold 
Table 13 Correlations between p-tau Thr181 levels and parameters in acoustic startle and prepulse inhibition

\begin{tabular}{|c|c|c|c|c|c|c|}
\hline \multirow[t]{2}{*}{ p-tau (Thr181) } & \multicolumn{2}{|l|}{ Pearson } & \multicolumn{2}{|c|}{ Kendall's tau-b } & \multicolumn{2}{|c|}{ Spearman's rho } \\
\hline & $\begin{array}{l}\text { Correlation } \\
\text { coefficient }\end{array}$ & $p$ value & $\begin{array}{l}\text { Correlation } \\
\text { coefficient }\end{array}$ & $p$ value & $\begin{array}{l}\text { Correlation } \\
\text { coefficient }\end{array}$ & $p$ value \\
\hline \multicolumn{7}{|l|}{ Left anterior cortex } \\
\hline Pulse-prepulse & -.245 & .496 & -.111 & .655 & -.067 & .855 \\
\hline PPI (\%) & .317 & .371 & .289 & .245 & .467 & .174 \\
\hline \multicolumn{7}{|c|}{ Right anterior cortex } \\
\hline Pulse-prepulse & -.221 & .539 & -.111 & .655 & -.042 & .907 \\
\hline PPI (\%) & .314 & .376 & .289 & .245 & .358 & .310 \\
\hline \multicolumn{7}{|l|}{ Left Hippocampus } \\
\hline Pulse-prepulse & -.520 & .123 & -.378 & .128 & -.503 & .138 \\
\hline PPI (\%) & -.047 & .898 & -.244 & .325 & -.333 & .347 \\
\hline \multicolumn{7}{|c|}{ Right Hippocampus } \\
\hline Pulse-prepulse & -.179 & .620 & -.156 & .531 & -.224 & .533 \\
\hline PPI (\%) & .430 & .215 & .244 & .215 & .418 & .229 \\
\hline \multicolumn{7}{|l|}{ Left Amygdala } \\
\hline Pulse-prepulse & .506 & .136 & .289 & .245 & .479 & .162 \\
\hline PPI (\%) & .146 & .688 & .244 & .325 & .164 & .651 \\
\hline \multicolumn{7}{|l|}{ Right Amygdala } \\
\hline Pulse-prepulse & -.240 & .505 & -.022 & .929 & -.127 & .726 \\
\hline PPI (\%) & -.105 & .774 & -.067 & .788 & -.091 & .803 \\
\hline \multicolumn{7}{|c|}{ Left Posterior Cortex } \\
\hline Pulse-prepulse & -.080 & .825 & -.067 & .788 & -.067 & .855 \\
\hline PPI (\%) & -.247 & .492 & -.022 & .929 & -.018 & .960 \\
\hline \multicolumn{7}{|c|}{ Right Posterior Cortex } \\
\hline Pulse-prepulse & .155 & .669 & .067 & .788 & .067 & .855 \\
\hline PPI (\%) & .151 & .677 & .111 & .655 & .127 & .726 \\
\hline
\end{tabular}

P-tau Thr181 levels were previously determined by Western blotting with the antibody AT270 at 40 weeks after blast exposure [21] and correlated with measures previously found to be affected in the same blast-exposed rats at 34 weeks following blast exposure [80]. Pulse refers to the first startle reading. Pulse-prepulse refers to background readings (prepulse) subtracted from the startle (pulse). Percent prepulse inhibition (PPI) was calculated with the formula $100-$ (startle response on acoustic prepulse plus pulse stimulus trials/pulse stimulus response alone trials) $\times 100]$. Five blast and five control animals were analyzed. There were no statistically significant correlations

Table 14 Summary of p-tau Thr181 and total tau correlations across brain regions with behavioral tests

\begin{tabular}{|c|c|c|c|c|c|c|}
\hline p-tau Thr181 & $\begin{array}{l}\text { Left anterior } \\
\text { cortex }\end{array}$ & $\begin{array}{l}\text { Right anterior } \\
\text { cortex }\end{array}$ & Left hippocampus & Right hippocampus & Left amygdala & $\begin{array}{l}\text { Right } \\
\text { amygdala }\end{array}$ \\
\hline EZM/LD & $\downarrow$ & $\downarrow$ & $\mathrm{NC}$ & $\downarrow$ & $\mathrm{NC}$ & $\mathrm{NC}$ \\
\hline Fear conditioning & $\uparrow$ & $\uparrow$ & $\mathrm{NC}$ & $\mathrm{NC}$ & $\mathrm{NC}$ & $\mathrm{NC}$ \\
\hline $\mathrm{NOL}$ & $\downarrow$ & $\downarrow$ & $\mathrm{NC}$ & $\downarrow$ & $\mathrm{NC}$ & $\mathrm{NC}$ \\
\hline Acoustic startle/PPI & $\mathrm{NC}$ & $\mathrm{NC}$ & $\mathrm{NC}$ & $\mathrm{NC}$ & $\mathrm{NC}$ & $\mathrm{NC}$ \\
\hline \multicolumn{7}{|l|}{ Total tau } \\
\hline EZM/LD & $\mathrm{NC}$ & $\mathrm{NC}$ & $\uparrow$ & $\mathrm{NC}$ & $\mathrm{NC}$ & $\mathrm{NC}$ \\
\hline Fear conditioning & $\mathrm{NC}$ & $\mathrm{NC}$ & $\mathrm{NC}$ & $\mathrm{NC}$ & $\mathrm{NC}$ & $\downarrow$ \\
\hline $\mathrm{NOL}$ & $\mathrm{NC}$ & $\mathrm{NC}$ & $\mathrm{NC}$ & $\mathrm{NC}$ & $\mathrm{NC}$ & $\mathrm{NC}$ \\
\hline Acoustic startle/PPI & NC & NC & NC & $\mathrm{NC}$ & NC & $\mathrm{NC}$ \\
\hline
\end{tabular}

$\uparrow=$ positive correlation; $\downarrow=$ negative correlation; NC = no correlation; EZM = elevated zero maze; LD = light/dark escape task; NOL $=$ novel object localization; $\mathrm{PPI}=$ prepulse inhibition 
conditioning task and p-tau levels in the left and right anterior cortical regions, which in our dissections include the neocortical regions most consistently considered to be part of the rat homolog of the primate prefrontal cortex [54]. The anterior cingulate cortex in our rat model was also a site of abnormal p-tau redistribution into neuronal perikarya [21]. Correlations did not reach statistical significance in the right hippocampus suggesting that anterior cortical function may be a more important determinant of this behavior.

These correlations are consistent with disinhibition models $[55,56,66]$ suggesting that $\mathrm{p}$-tau accumulation causing impaired anterior cortical function leads to disinhibited amygdala function without any p-tau elevation or pathology in the amygdala itself (Fig. 7). The fact that in blast-exposed rats, behavioral effects including altered fear learning can be rescued by a drug that stimulates hippocampal neurogenesis further supports the role of hippocampal influences on amygdala function in these animals [79]. It is interesting that one of the few correlations between behavior and total tau was with fear conditioning in the right amygdala where a negative correlation was found between total tau and freezing. The physiological meaning of this and its relationship, if any, to p-tau changes in other regions is unclear. We have observed increases in stathmin 1 expression in the amygdala of blast-exposed animals 9 months after exposure [26]. Stathmin 1 is another microtubule-associated protein that is central in the regulation of fear responses in the amygdala [90]. Further study will be required to determine whether accumulation of phosphorylated tau species in the anterior cortex bears any relationship to stathmin expression changes in the amygdala.

There were no correlations between p-tau levels and responses to acoustic startle or prepulse inhibition. Disordered regulation of these responses are thought to be the basis of the hyperarousal that is a core feature of PTSD [103]. The startle reflex and prepulse inhibition tests depend on the functional integrity of connections within the pons, thalamic intralaminar nuclei, and reticular formation, with forebrain regions likely also playing a role as part of their regulation of complex behavioral states $[36,81,106]$. While we did not measure p-tau levels in these structures, there was no correlation with $\mathrm{p}$-tau levels in the anterior cortical or right hippocampal regions suggesting that tau pathology in these regions is not causing disordered acoustic startle reactions or altered prepulse inhibition.

While not as specific to PTSD as other traits, anxiety is a core-associated feature of PTSD [103]. Tests of anxiety in rodents such as the elevated zero maze or light dark escape task are heavily dependent on anterior cortical and hippocampal regions $[81,93]$. Increased p-tau levels in left and right anterior cortical regions as well as the right hippocampus were associated with increased anxiety in multiple measures in these tasks (Table 14).

The laterality of the p-tau accumulation remains puzzling. This effect was most striking in the hippocampus where the right side was always affected but never the left (Table 3). In the anterior cortex, the left side was not affected unless the right was as well. One explanation for this laterality would be if the blast exposure were delivered asymmetrically. Indeed, Turner et al. [101] have described asymmetric p-tau accumulation following both blast and closed head injury models in rats. However, in these studies, the blast exposure and closed head injuries were administered to one side of the head. In our model, the blast exposure is delivered as a straight frontal exposure [1] and there should be no systematic variation in the rat's placement within the blast tube that would cause the right hemisphere to be differentially affected.

We can only speculate that these patterns reflect some laterality of hemispheric function in the rat that causes the right side to respond differently to the initial insult or reflects a feature of how the injury evolves over time. Structural and functional asymmetries in human brain neuroimaging are well known [45] and multiple studies have noted brain asymmetries in blast-exposed veterans in a variety of imaging modalities including diffusion tensor imaging (DTI), functional magnetic resonance imaging (fMRI) and ${ }^{18} \mathrm{~F}$-fluorodeoxyglucose (FDG-PET) metabolism [33, 41, 65, 74, 94, 95, 98, 102, 105, 108].

The asymmetrical effects on the right and left hippocampus were particularly striking with all three cohorts showing increased tau phosphorylation specifically in the right hippocampus (Table 4). Differences between the right and left hippocampus in rats are well established [3, 6, 8, 85, 97]. Proteomic profiles differ between the rat left and right hippocampus [85]. Brainderived neurotrophic factor expression is higher in the rat right hippocampus [3] while during development the expression of the $\alpha 7$ and $\alpha 4$ subunits of nicotinic acetylcholine receptors is higher in the left hippocampus [6]. Insulin-like growth factor-1 receptors show sexually dimorphic patterns of expression [40]. Hippocampal asymmetries also affect serotonergic [8] and angiotensin II [97] modulation of learning and memory in rats. Tau affects stress responses in mice [60] and hemispheric asymmetries have been observed in brain-derived neurotrophic factor and neurotrophic tyrosine kinase receptor type 3 expression in stress-resilient rats [31]. Whether asymmetries in p-tau expression could also be part of a lateralized stress response is unknown.

The results were specific to $\mathrm{p}$-tau Thr181 in that there were no consistent correlations between phosphorylation and behavioral assessments with three other sites 


\section{a}
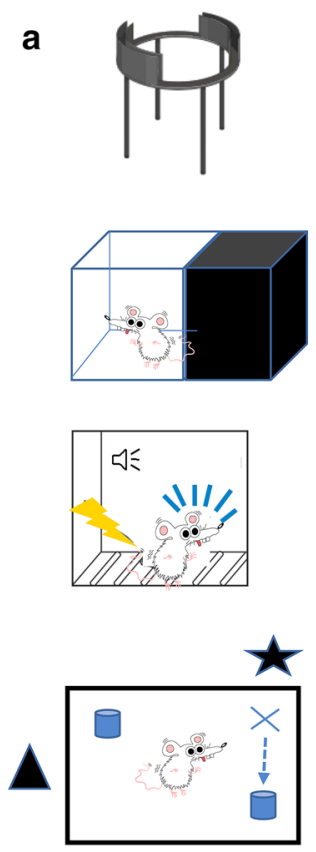

(correlation) (p-tau)

\section{EZM:}

$\downarrow$ Move distance

$\downarrow$ Open arm time

- Cross arm

latency

Light/dark:

- $\downarrow$ light side time

and distance

Fear conditioning -个Cued freezing

Novel object localization:

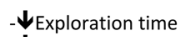

- $\downarrow$ Discrimination

index
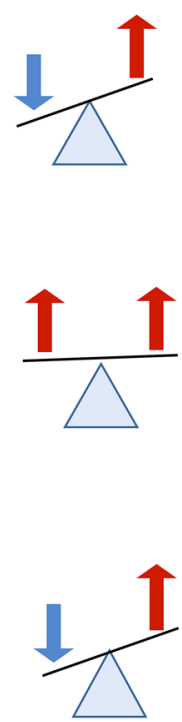

b

\section{Phosphorylated Thr181}

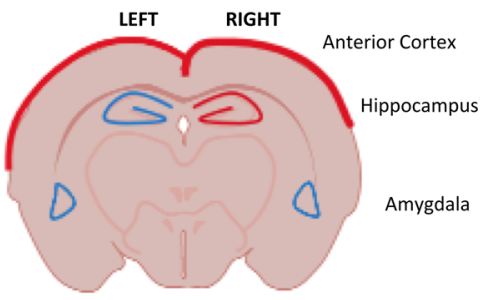

Increased; Unchanged

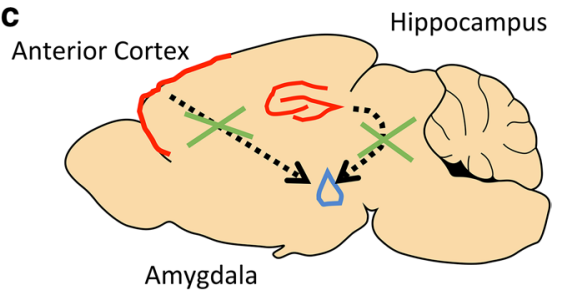

Fig. 7 Selected examples illustrating correlations of p-tau Thr181 with behavior. Panel a lists behavioral parameters altered in blast-exposed rats at 29 to 35 weeks and correlations with p-tau Thr 181 levels at 40 weeks after blast exposure. Panel b shows p-tau Thr181 changes in the indicated brain areas. Panel $\mathbf{c}$ shows proposed correlation between p-tau accumulation in anterior cortical regions and hippocampus leading to disinhibited amygdala function. Inhibition is indicated by the crosses through the dashed arrows

(Thr231, Ser396, and Ser404) whose phosphorylation status was not changed following blast [21]. Interestingly, p-tau Thr181 is elevated in plasma-borne exosomes from U.S. military veterans with TBI [49]. Among these TBI veterans, exosomal p-tau Thr181 levels also correlated positively with affective symptoms and PTSD severity [49].

Tau phosphorylation is complex with over 80 potential phosphorylation sites, of which over 40 have been observed experimentally [48, 104]. Thr 181 is located in the proline-rich region, which contains multiple ThrPro or Ser-Pro motifs, which are targets for prolinedirected kinases including glycogen synthase kinase $3 \beta$, cyclin-dependent kinase 5 (CDK5), mitogen-activated protein kinase (MAPK) and JUN N-terminal kinase (JNK) [104]. Multiple sites in the proline-rich region are extensively phosphorylated in Alzheimer's disease [104]. P-Thr181 is deposited in the paired helical filaments found in human NFTs [38] and its level in cerebrospinal fluid is an established biomarker in Alzheimer's disease as well as a predictor of future cognitive decline [25]. Plasma p-tau Thr181 concentrations are increased in Alzheimer's disease and strongly correlate with amyloid beta-PET-positivity and cortical tau protein deposition as judged by (18)F-flortaucipir PET [99].

\section{Conclusions}

Independent of how blast preferentially modifies phosphorylation at Thr181, this study shows that the laterality and region-specific pattern of its phosphorylation correlate with PTSD-related behavioral traits in rats exposed to repetitive low-level blast. These patterns are consistent with biological models of PTSD suggesting that anterior cortical and hippocampal dysfunction lead to disinhibited amygdala function. These findings provide further evidence for a link between blast injury and tauopathies, which has implications for understanding the relationship of chronic blast-related neurobehavioral syndromes in humans to neurodegenerative diseases.

\section{Acknowledgements}

This work was supported by the Department of Veterans Affairs, Veterans Health Administration, Rehabilitation Research and Development Service Awards 1101 RX000996 (GE), 1101 RX002660 (GE), 1121 RX003019 (GE), 1101 RX000684 (SG), and 1101RX002333 (SG), the Department of Veterans Affairs Office of Research and Development Medical Research Service 1101 BX004067 (GE) and 1101BX002311 (DC), Department of Defense work unit number 0000B999.0000.000.A1503 (STA), the Alzheimer's Drug Discovery Foundation (SG) and by P50AG005138 and P30AG066514 to Mary Sano (SG, $\mathrm{PRH}$ ). All studies involving animals were reviewed and approved by the Institutional Animal Care and Use Committees of the Walter Reed Army Institute of Research (WRAIR)/Naval Medical Research Center and the James J. Peters VA Medical Center. Studies were conducted in compliance with the Public Health Service policy on the humane care and use of laboratory animals, the $\mathrm{NIH}$ Guide for the Care and Use of Laboratory Animals, and all applicable 
Federal regulations governing the protection of animals in research. The views expressed in this article reflect the results of research conducted by the authors and do not necessarily reflect the official policy or position of the Uniformed Services University of the Health Sciences (USUHS), The Henry M. Jackson Foundation for the Advancement of Military Medicine, Inc., the Department of the Navy, or the Department of Defense (DoD). Mention of trade names, commercial products, or organizations does not imply endorsement by the U.S. Government. Some of the authors are military service members or federal/contracted employees of the United States Government. This work was prepared as part of my official duties. Title 17 U.S.C. § 105 provides that 'Copyright protection under this title is not available for any work of the United States Government.'Title 17 U.S.C. § 101 defines a U.S. Government work as a work prepared by a military service member or employee of the U.S. Government as part of that person's official duties.

\section{Author contributions}

Study design (GPG, RDG, STA GAE); conducted experiments (GPG, RDG, GMP, AOP, DP, RA, UK); analyzed data (GPG, RDG, GAE); wrote manuscript (GPG, RDG, $\mathrm{GAE})$; provided critical scientific input in manuscript preparation and interpreting results (MAG, PRH, DLD, DGC, SG, STA).

\section{Funding}

This work was supported by the Department of Veterans Affairs, Veterans Health Administration, Rehabilitation Research and Development Service Awards 1101RX000996 (GE), $1101 \mathrm{RX002660}$ (GE), $1121 \mathrm{RX003019}$ (GE), $1101 R X 000684$ (SG), and 1101RX002333 (SG), the Department of Veterans Affairs Office of Research and Development Medical Research Service $1101 B X 004067$ (GE) and 1101BX002311 (DC), Department of Defense work unit number 0000B999.0000.000.A1503 (STA), the Alzheimer's Drug Discovery Foundation (SG) and by P50AG005138 and P30AG066514 to Mary Sano (SG, $\mathrm{PRH}$ ). The funding agencies played no role in the design of the study and collection, analysis, and interpretation of data or in writing the manuscript.

\section{Availability of data and materials}

The datasets analyzed during the current study are available from the corresponding author on reasonable request.

\section{Competing interests}

The authors declare no competing interests.

\section{Ethics approval}

All studies involving animals were reviewed and approved by the Institutional Animal Care and Use Committees of the Walter Reed Army Institute of Research (WRAIR) Naval Medical Research Center and the James J. Peters VA Medical Center.

\section{Author details}

${ }^{1}$ Research and Development Service, James J. Peters Department of Veterans Affairs Medical Center, 130 West Kingsbridge Road, Bronx, NY 10468, USA. 2 Department of Neurology, Icahn School of Medicine At Mount Sinai, One Gustave Levy Place, New York, NY 10029, USA. ${ }^{3}$ Department of Psychiatry, Icahn School of Medicine At Mount Sinai, One Gustave Levy Place, New York, NY 10029, USA. ${ }^{4}$ General Medical Research Service, James J. Peters Department of Veterans Affairs Medical Center, 130 West Kingsbridge Road, Bronx, NY 10468, USA. ${ }^{5}$ Department of Neurotrauma, Naval Medical Research Center, 503 Robert Grant Avenue, Silver Spring, MD 20910, USA. ${ }^{6}$ The Henry M. Jackson Foundation for the Advancement of Military Medicine, Inc., Bethesda, MD, USA. ${ }^{7}$ Nash Family Department of Neuroscience and Friedman Brain Institute, Icahn School of Medicine At Mount Sinai, One Gustave Levy Place, New York, NY 10029, USA. ${ }^{8}$ Department of Geriatrics and Palliative Care, Icahn School of Medicine At Mount Sinai, One Gustave Levy, New York, NY 10029, USA. ${ }^{9}$ Mount Sinai Alzheimer's Disease Research Center and Ronald M. Loeb Center for Alzheimer's Disease, Icahn School of Medicine At Mount Sinai, One Gustave Levy Place, New York, NY 10029, USA. ${ }^{10}$ Department of Pathology, Uniformed Services University of Health Sciences, 4301 Jones Bridge Rd., Bethesda, MD 20814, USA. ${ }^{11}$ Center for Neuroscience and Regenerative Medicine, Uniformed Services University of Health Sciences, 4301 Jones Bridge Rd., Bethesda, MD 20814, USA. ${ }^{12}$ Geriatric Research Education and Clinical Center, VA Puget Sound Health Care System, 1660 S Columbian Way, Seattle, WA 98108, USA. ${ }^{13}$ Department of Medicine, University of Washington, 1959 NE Pacific St, Seattle, WA 98195, USA. ${ }^{14}$ Barbara and Maurice A. Deane Center for Wellness and Cognitive Health, and Mount Sinai NFL Neurological Care Center, Icahn School of Medicine At Mount Sinai, 5 East 98th Street, New York, NY 10029, USA. ${ }^{15}$ Neurology Service, James J. Peters Department of Veterans Affairs Medical Center, Neurology Service (3E16), 130 West Kingsbridge Road, Bronx, NY 10468, USA.

Received: 30 December 2020 Accepted: 7 February 2021

Published online: 01 March 2021

\section{References}

1. Ahlers ST, Vasserman-Stokes E, Shaughness MC, Hall AA, Shear DA, Chavko M, McCarron RM, Stone JR (2012) Assessment of the effects of acute and repeated exposure to blast overpressure in rodents: toward a greater understanding of blast and the potential ramifications for injury in humans exposed to blast. Front Neurol 3:32

2. Ahmed F, Plantman S, Cernak I, Agoston DV (2015) The temporal pattern of changes in serum biomarker levels reveals complex and dynamically changing pathologies after exposure to a single lowintensity blast in mice. Front Neurol 6:114. https://doi.org/10.3389/fneur 2015.00114

3. Almeida FB, Gomez R, Barros HMT, Nin MS (2019) Hemispheredependent changes in mRNA expression of GABAA receptor subunits and BDNF after intra-prefrontal cortex allopregnanolone infusion in rats. Neuroscience 397:56-66. https://doi.org/10.1016/j.neuroscien ce.2018.11.029

4. Arun P, Abu-Taleb R, Oguntayo S, Tanaka M, Wang Y, Valiyaveettil M, Long JB, Zhang Y, Nambiar MP (2013) Distinct patterns of expression of traumatic brain injury biomarkers after blast exposure: role of compromised cell membrane integrity. Neurosci Lett 552:87-91. https://doi. org/10.1016/j.neulet.2013.07.047

5. Arun P, Oguntayo S, Albert SV, Gist I, Wang Y, Nambiar MP, Long JB (2015) Acute decrease in alkaline phosphatase after brain injury: a potential mechanism for tauopathy. Neurosci Lett 609:152-158. https:// doi.org/10.1016/j.neulet.2015.10.036

6. Baradaran R, Khoshdel-Sarkarizi H, Kargozar S, Hami J, Mohammadipour A, Sadr-Nabavi A, Peyvandi Karizbodagh M, Kheradmand $\mathrm{H}$, Haghir $\mathrm{H}$ (2020) Developmental regulation and lateralisation of the alpha7 and alpha4 subunits of nicotinic acetylcholine receptors in developing rat hippocampus. Int J Dev Neurosci 80:303-318. https://doi.org/10.1002/ jdn.10026

7. Barten DM, Fanara P, Andorfer C, Hoque N, Wong PY, Husted KH, Cadelina GW, Decarr LB, Yang L, Liu V et al (2012) Hyperdynamic microtubules, cognitive deficits, and pathology are improved in tau transgenic mice with low doses of the microtubule-stabilizing agent BMS-241027. J Neurosci 32:7137-7145. https://doi.org/10.1523/JNEUR OSCI.0188-12.2012

8. Belcheva I, Tashev R, Belcheva S (2007) Hippocampal asymmetry in serotonergic modulation of learning and memory in rats. Laterality 12:475-486. https://doi.org/10.1080/13576500701453983

9. Berridge C, Espana R, Stalnaker T (2003) Stress and coping: asymmetry of dopamine efferents within the prefrontal cortex. In: Hugdahl K, Davidison R (eds) The Asymmetrical Brain. MIT Press, Cambridge, MA, pp 69-103

10. Brunden KR, Zhang B, Carroll J, Yao Y, Potuzak JS, Hogan AM, Iba M, James MJ, Xie SX, Ballatore C et al (2010) Epothilone D improves microtubule density, axonal integrity, and cognition in a transgenic mouse model of tauopathy. J Neurosci 30:13861-13866. https://doi. org/10.1523/JNEUROSCI.3059-10.2010

11. Bugay V, Bozdemir E, Vigil FA, Chun SH, Holstein DM, Elliott WR, Sprague CJ, Cavazos JE, Zamora DO, Rule G et al (2020) A mouse model of repetitive blast traumatic brain injury reveals post-trauma seizures and increased neuronal excitability. J Neurotrauma 37:248-261. https://doi. org/10.1089/neu.2018.6333

12. Butler RW, Braff DL, Rausch JL, Jenkins MA, Sprock J, Geyer MA (1990) Physiological evidence of exaggerated startle response in a subgroup of Vietnam veterans with combat-related PTSD. Am J Psychiatry 147:1308-1312 
13. Cao J, Gaamouch FE, Meabon JS, Meeker KD, Zhu L, Zhong MB, Bendik J, Elder G, Jing P, Xia J et al (2017) ApoE4-associated phospholipid dysregulation contributes to development of Tau hyper-phosphorylation after traumatic brain injury. Sci Rep 7:11372. https://doi.org/10.1038/ s41598-017-11654-7

14. Castellano MA, Diaz-Palarea MD, Rodriguez M, Barroso J (1987) Lateralization in male rats and dopaminergic system: evidence of right-side population bias. Physiol Behav 40:607-612

15. Cernak I, Stein DG, Elder GA, Ahlers S, Curley K, DePalma RG, Duda J, Ikonomovic M, Iverson GL, Kobeissy F et al (2017) Preclinical modelling of militarily relevant traumatic brain injuries: Challenges and recommendations for future directions. Brain Inj 31:1168-1176. https://doi. org/10.1080/02699052.2016.1274779

16. Chavko M, Koller WA, Prusaczyk WK, McCarron RM (2007) Measurement of blast wave by a miniature fiber optic pressure transducer in the rat brain. J Neurosci Methods 159:277-281

17. Chen M, Song H, Cui J, Johnson CE, Hubler GK, DePalma RG, Gu Z, Xia W (2018) Proteomic profiling of mouse brains exposed to blastinduced mild traumatic brain injury reveals changes in axonal proteins and phosphorylated tau. J Alzheimers Dis 66:751-773. https://doi. org/10.3233/JAD-180726

18. DeKosky ST, Blennow K, Ikonomovic MD, Gandy S (2013) Acute and chronic traumatic encephalopathies: pathogenesis and biomarkers. Nat Rev Neurol 9:192-200. https://doi.org/10.1038/nrneurol.2013.36

19. DeKosky ST, Ikonomovic MD, Gandy S (2010) Traumatic brain injury: football, warfare, and long-term effects. N Engl J Med 363:1293-1296

20. Denenberg $\vee(1981)$ Hemispheric laterality in animals and the effects of early experience. Behav Brain Sci 4:1-49

21. Dickstein DL, De Gasperi R, Gama Sosa MA, Perez Garcia G, Short JA, Sosa H, Perez GM, Tschiffely AE, Dams-O'Connor K, Pullman MY et al (2020) Brain and blood biomarkers of tauopathy and neuronal injury in humans and rats with neurobehavioral syndromes following blast exposure. Mol Psychiatry. https://doi.org/10.1038/s41380-020-0674-z

22. Du X, West MB, Cai Q, Cheng W, Ewert DL, Li W, Floyd RA, Kopke RD (2017) Antioxidants reduce neurodegeneration and accumulation of pathologic Tau proteins in the auditory system after blast exposure. Free Radic Biol Med 108:627-643. https://doi.org/10.1016/j.freeradbio med.2017.04.343

23. Du X, West MB, Cheng W, Ewert DL, Li W, Saunders D, Towner RA, Floyd RA, Kopke RD (2016) Ameliorative effects of antioxidants on the hippocampal accumulation of pathologic tau in a rat model of blastinduced traumatic brain injury. Oxid Med Cell Longev 2016:4159357. https://doi.org/10.1155/2016/4159357

24. Dujardin S, Hyman BT (2019) Tau prion-like propagation: state of the art and current challenges. Adv Exp Med Biol 1184:305-325. https://doi. org/10.1007/978-981-32-9358-8_23

25. Dumurgier J, Hanseeuw BJ, Hatling FB, Judge KA, Schultz AP, Chhatwal JP, Blacker D, Sperling RA, Johnson KA, Hyman BT et al (2017) Alzheimer's disease biomarkers and future decline in cognitive normal older adults. J Alzheimers Dis 60:1451-1459. https://doi.org/10.3233/JAD170511

26. Elder GA, Dorr NP, De Gasperi R, Gama Sosa MA, Shaughness MC, Maudlin-Jeronimo E, Hall AA, McCarron RM, Ahlers ST (2012) Blast exposure induces post-traumatic stress disorder-related traits in a rat model of mild traumatic brain injury. J Neurotrauma 29:2564-2575. https://doi. org/10.1089/neu.2012.2510

27. Elder GA, Ehrlich ME, Gandy S (2019) Relationship of traumatic brain injury to chronic mental health problems and dementia in military veterans. Neurosci Lett 707:134294. https://doi.org/10.1016/j.neule t.2019.134294

28. Elder GA, Mitsis EM, Ahlers ST, Cristian A (2010) Blast-induced mild traumatic brain injury. Psychiatr Clin N Am 33:757-781

29. Engel C, Hoch E, Simmons M (2019) The neurological effects of repeated exposure to military occupational blast: implications for prevention and health: proceedings, findings, and expert recommendations from the Seventh Department of Defense State-of-the-Science Meeting. Rand Corporation, Santa Monica, CA

30. Falcon B, Zivanov J, Zhang W, Murzin AG, Garringer HJ, Vidal R, Crowther RA, Newell KL, Ghetti B, Goedert M et al (2019) Novel tau filament fold in chronic traumatic encephalopathy encloses hydrophobic molecules. Nature 568:420-423. https://doi.org/10.1038/s41586-019-1026-5
31. Farhang S, Barar J, Fakhari A, Mesgariabbasi M, Khani S, Omidi Y, Farnam A (2014) Asymmetrical expression of BDNF and NTRK3 genes in frontoparietal cortex of stress-resilient rats in an animal model of depression. Synapse 68:387-393. https://doi.org/10.1002/syn.21746

32. Field A (2018) Discovering statistics using IBM SPSS statistics. SAGE Publications Ltd, Thousand Oaks, CA

33. Fischer $B L$, Parsons M, Durgerian $S$, Reece $C$, Mourany L, Lowe MJ, Beall EB, Koenig KA, Jones SE, Newsome MR et al (2014) Neural activation during response inhibition differentiates blast from mechanical causes of mild to moderate traumatic brain injury. J Neurotrauma 31:169-179. https://doi.org/10.1089/neu.2013.2877

34. Gandy S, Ikonomovic MD, Mitsis E, Elder G, Ahlers ST, Barth J, Stone JR, DeKosky ST (2014) Chronic traumatic encephalopathy: clinicalbiomarker correlations and current concepts in pathogenesis. Mol Neurodegener 9:37. https://doi.org/10.1186/1750-1326-9-37

35. Gerson J, Castillo-Carranza DL, Sengupta U, Bodani R, Prough DS, DeWitt DS, Hawkins BE, Kayed R (2016) Tau oligomers derived from traumatic brain injury cause cognitive impairment and accelerate onset of pathology in htau mice. J Neurotrauma 33:2034-2043. https://doi. org/10.1089/neu.2015.4262

36. Geyer MA, Swerdlow NR (2001) Measurement of startle response, prepulse inhibition, and habituation. Curr Protoc Neurosci. https://doi. org/10.1002/0471142301.ns0807s03

37. Ghajari M, Hellyer PJ, Sharp DJ (2017) Computational modelling of traumatic brain injury predicts the location of chronic traumatic encephalopathy pathology. Brain 140:333-343. https://doi.org/10.1093/ brain/aww317

38. Goedert M, Jakes R, Crowther RA, Cohen P, Vanmechelen E, Vandermeeren M, Cras P (1994) Epitope mapping of monoclonal antibodies to the paired helical filaments of Alzheimer's disease: identification of phosphorylation sites in tau protein. Biochem J 301(Pt 3):871-877

39. Goldstein LE, Fisher AM, Tagge CA, Zhang XL, Velisek L, Sullivan JA, Upreti C, Kracht JM, Ericsson M, Wojnarowicz MW et al (2012) Chronic traumatic encephalopathy in blast-exposed military veterans and a blast neurotrauma mouse model. Sci Transl Med 4:134ra160

40. Hami J, Kheradmand H, Haghir H (2014) Gender differences and lateralization in the distribution pattern of insulin-like growth factor-1 receptor in developing rat hippocampus: an immunohistochemical study. Cell Mol Neurobiol 34:215-226. https://doi.org/10.1007/s10571-013-0005-x

41. Hayes JP, Miller DR, Lafleche G, Salat DH, Verfaellie M (2015) The nature of white matter abnormalities in blast-related mild traumatic brain injury. Neuroimage Clin 8:148-156. https://doi.org/10.1016/j. nicl.2015.04.001

42. Howell D (2012) Statistical methods for psychology. Wadsworth Cengage Learning, Wadsworth City

43. Huber BR, Meabon JS, Hoffer ZS, Zhang J, Hoekstra JG, Pagulayan KF, McMillan PJ, Mayer CL, Banks WA, Kraemer BC et al (2016) Blast exposure causes dynamic microglial/macrophage responses and microdomains of brain microvessel dysfunction. Neuroscience 319:206-220. https://doi.org/10.1016/j.neuroscience.2016.01.022

44. Huber BR, Meabon JS, Martin TJ, Mourad PD, Bennett R, Kraemer BC, Cernak I, Petrie EC, Emery MJ, Swenson ER et al (2013) Blast exposure causes early and persistent aberrant phospho- and cleaved-tau expression in a murine model of mild blast-induced traumatic brain injury. J Alzheimers Dis 37:309-323. https://doi.org/10.3233/JAD-130182

45. Hugdahl K (2011) Hemispheric asymmetry: contributions from brain imaging. Wiley Interdiscip Rev Cogn Sci 2:461-478. https://doi. org/10.1002/wCs.122

46. lacono D, Lee P, Edlow BL, Gray N, Fischl B, Kenney K, Lew HL, Lozanoff S, Liacouras P, Lichtenberger J et al (2020) Early-onset dementia in war veterans: brain polypathology and clinicopathologic complexity. J Neuropathol Exp Neurol 79:144-162. https://doi.org/10.1093/jnen/nlz122

47. Jablonski SA, Schreiber WB, Westbrook SR, Brennan LE, Stanton ME (2013) Determinants of novel object and location recognition during development. Behav Brain Res 256:140-150. https://doi.org/10.1016/j. bbr.2013.07.055

48. Johnson GV, StoothoffWH (2004) Tau phosphorylation in neuronal cell function and dysfunction. J Cell Sci 117:5721-5729. https://doi. org/10.1242/jcs.01558

49. Kenney K, Qu BX, Lai C, Devoto C, Motamedi V, Walker WC, Levin HS, Nolen T, Wilde EA, Diaz-Arrastia R et al (2018) Higher exosomal 
phosphorylated tau and total tau among veterans with combat-related repetitive chronic mild traumatic brain injury. Brain Inj 32:1276-1284. https://doi.org/10.1080/02699052.2018.1483530

50. Klur S, Muller C, Pereira de Vasconcelos A, Ballard T, Lopez J, Galani R, Certa U, Cassel JC (2009) Hippocampal-dependent spatial memory functions might be lateralized in rats: an approach combining gene expression profiling and reversible inactivation. Hippocampus 19:800-816. https://doi.org/10.1002/hipo.20562

51. Kovacs GG (2015) Invited review: Neuropathology of tauopathies: principles and practice. Neuropathol Appl Neurobiol 41:3-23. https:// doi.org/10.1111/nan.12208

52. Kovesdi E, Gyorgy AB, Kwon SK, Wingo DL, Kamnaksh A, Long JB, Kasper CE, Agoston DV (2011) The effect of enriched environment on the outcome of traumatic brain injury; a behavioral, proteomics, and histological study. Front Neurosci 5:42

53. Lange RT, Brickell TA, Ivins B, Vanderploeg RD, French LM (2013) Variable, not always persistent, postconcussion symptoms after mild TBI in U.S. military service members: a five-year cross-sectional outcome study. J Neurotrauma 30:958-969. https://doi.org/10.1089/neu.2012.2743

54. Laubach M, Amarante LM, Swanson K, White SR (2018) What, if anything, is rodent prefrontal cortex? eNeuro. https://doi.org/10.1523/ ENEURO.0315-18.2018

55. Liberzon I, Abelson JL (2016) Context processing and the neurobiology of post-traumatic stress disorder. Neuron 92:14-30. https://doi. org/10.1016/j.neuron.2016.09.039

56. Liberzon I, Sripada CS (2008) The functional neuroanatomy of PTSD: a critical review. Prog Brain Res 167:151-169

57. Liu MD, Luo P, Wang ZJ, Fei Z (2014) Changes of serum Tau, GFAP, TNFalpha and malonaldehyde after blast-related traumatic brain injury. Chin J Traumatol 17:317-322

58. Logsdon AF, Lucke-Wold BP, Turner RC, Li X, Adkins CE, Mohammad AS, Huber JD, Rosen CL, Lockman PR (2017) A mouse model of focal vascular injury induces astrocyte reactivity, tau oligomers, and aberrant behavior. Arch Neurosci 4:e44254

59. Logsdon AF, Schindler AG, Meabon JS, Yagi M, Herbert MJ, Banks WA, Raskind MA, Marshall DA, Keene CD, Perl DP et al (2020) Nitric oxide synthase mediates cerebellar dysfunction in mice exposed to repetitive blast-induced mild traumatic brain injury. Sci Rep 10:9420. https://doi. org/10.1038/s41598-020-66113-7

60. Lopes S, Vaz-Silva J, Pinto V, Dalla C, Kokras N, Bedenk B, Mack N, Czisch M, Almeida OF, Sousa N et al (2016) Tau protein is essential for stressinduced brain pathology. Proc Natl Acad Sci USA 113:E3755-3763. https ://doi.org/10.1073/pnas.1600953113

61. Lucke-Wold BP, Logsdon AF, Turner RC, Huber JD, Rosen CL (2017) Endoplasmic reticulum stress modulation as a target for ameliorating effects of blast induced traumatic brain injury. J Neurotrauma 34:S62S70. https://doi.org/10.1089/neu.2016.4680

62. Lucke-Wold BP, Naser ZJ, Logsdon AF, Turner RC, Smith KE, Robson MJ, Bailes JE, Lee JM, Rosen CL, Huber JD (2015) Amelioration of nicotinamide adenine dinucleotide phosphate-oxidase mediated stress reduces cell death after blast-induced traumatic brain injury. Transl Res 166(509-528):e501. https://doi.org/10.1016/j.trsl.2015.08.005

63. Lucke-Wold BP, Turner RC, Logsdon AF, Nguyen L, Bailes JE, Lee JM, Robson MJ, Omalu BI, Huber JD, Rosen CL (2016) Endoplasmic reticulum stress implicated in chronic traumatic encephalopathy. J Neurosurg 124:687-702. https://doi.org/10.3171/2015.3.JNS141802

64. Mac Donald CL, Barber J, Jordan M, Johnson AM, Dikmen S, Fann JR, Temkin N (2017) Early clinical predictors of 5-year outcome after concussive blast traumatic brain injury. JAMA Neurol 74:821-829. https ://doi.org/10.1001/jamaneurol.2017.0143

65. Mac Donald CL, Johnson AM, Cooper D, Nelson EC, Werner NJ, Shimony JS, Snyder AZ, Raichle ME, Witherow JR, Fang R et al (2011) Detection of blast-related traumatic brain injury in U.S. military personnel. N Engl J Med 364:2091-2100. https://doi.org/10.1056/NEJMoa1008069

66. Mahan AL, Ressler KJ (2012) Fear conditioning, synaptic plasticity and the amygdala: implications for posttraumatic stress disorder. Trends Neurosci 35:24-35

67. Mammadova N, Ghaisas S, Zenitsky G, Sakaguchi DS, Kanthasamy AG, Greenlee JJ, West Greenlee MH (2017) Lasting retinal injury in a mouse model of blast-induced trauma. Am J Pathol 187:1459-1472. https:// doi.org/10.1016/j.ajpath.2017.03.005
68. McKee AC, Abdolmohammadi B, Stein TD (2018) The neuropathology of chronic traumatic encephalopathy. Handb Clin Neurol 158:297-307. https://doi.org/10.1016/B978-0-444-63954-7.00028-8

69. McKee AC, Stern RA, Nowinski CJ, Stein TD, Alvarez VE, Daneshvar DH, Lee HS, Wojtowicz SM, Hall G, Baugh CM et al (2013) The spectrum of disease in chronic traumatic encephalopathy. Brain 136:43-64. https:// doi.org/10.1093/brain/aws307

70. Meabon JS, Huber BR, Cross DJ, Richards TL, Minoshima S, Pagulayan KF, Li G, Meeker KD, Kraemer BC, Petrie EC et al (2016) Repetitive blast exposure in mice and combat veterans causes persistent cerebellar dysfunction. Sci Transl Med 8:321ra326. https://doi.org/10.1126/scitr ansImed.aaa9585

71. Mohamed AZ, Cumming P, Gotz J, Nasrallah F, Department of Defense Alzheimer's Disease Neuroimaging Initiative (2019) Tauopathy in veterans with long-term posttraumatic stress disorder and traumatic brain injury. Eur J Nucl Med Mol Imaging 46:1139-1151. https://doi. org/10.1007/s00259-018-4241-7

72. Morgan CA 3rd, Grillon C, Southwick SM, Davis M, Charney DS (1996) Exaggerated acoustic startle reflex in Gulf War veterans with posttraumatic stress disorder. Am J Psychiatry 153:64-68

73. Murphy EK, lacono D, Pan H, Grimes JB, Parks S, Raiciulescu S, Leonessa F, Perl DP (2020) Explosive-driven double-blast exposure: molecular, histopathological, and behavioral consequences. Sci Rep 10:17446. https://doi.org/10.1038/s41598-020-74296-2

74. Newsome MR, Mayer AR, Lin X, Troyanskaya M, Jackson GR, Scheibel RS, Walder A, Sathiyaraj A, Wilde EA, Mukhi S et al (2016) Chronic effects of blast-related TBI on subcortical functional connectivity in veterans. J Int Neuropsychol Soc 22:631-642. https://doi.org/10.1017/S135561771 6000448

75. Olivera A, Lejbman N, Jeromin A, French LM, Kim HS, Cashion A, Mysliwiec V, Diaz-Arrastia R, Gill J (2015) Peripheral Total Tau in Military Personnel Who Sustain Traumatic Brain Injuries During Deployment. JAMA neurology 72:1109-1116. https://doi.org/10.1001/jamaneurol .2015 .1383

76. Omalu B, Hammers JL, Bailes J, Hamilton RL, Kamboh MI, Webster G, Fitzsimmons RP (2011) Chronic traumatic encephalopathy in an Iraqi war veteran with posttraumatic stress disorder who committed suicide. Neurosurg Focus 31:E3. https://doi.org/10.3171/2011.9.FOCUS11178

77. Orr SP, Lasko NB, Shalev AY, Pitman RK (1995) Physiologic responses to loud tones in Vietnam veterans with posttraumatic stress disorder. J Abnorm Psychol 104:75-82

78. Perez Garcia G, Perez GM, De Gasperi R, Gama Sosa MA, Otero-Pagan A, Pryor D, Abutarboush R, Kawoos U, Hof P, Cook D et al (2020) Progressive cognitive and PTSD-related behavioral traits in rats exposed to repetitive low-level blast. J Neurotrauma. https://doi.org/10.1089/ neu.2020.7398

79. Perez Garcia G, De Gasperi R, Gama Sosa MA, Perez GM, Otero-Pagan A, Tschiffely A, McCarron RM, Ahlers ST, Elder GA, Gandy S (2018) PTSD-related behavioral traits in a rat model of blast-induced $\mathrm{mTBI}$ are reversed by the $\mathrm{mGluR2/3}$ receptor antagonist $\mathrm{BCl}-838$. eNeuro. https:// doi.org/10.1523/ENEURO.0357-17.2018

80. Perez Garcia G, Gama Sosa MA, De Gasperi R, Lashof-Sullivan M, Maudlin-Jeronimo E, Stone JR, Haghighi F, Ahlers ST, Elder GA (2018) Chronic post-traumatic stress disorder-related traits in a rat model of low-level blast exposure. Behav Brain Res 340:117-125. https://doi.org/10.1016/j. bbr.2016.09.061

81. Perez Garcia G, Gama Sosa MA, De Gasperi R, Tschiffely AE, McCarron RM, Hof PR, Gandy S, Ahlers ST, Elder GA (2019) Blast-induced "PTSD": Evidence from an animal model. Neuropharmacology 145:220-229. https://doi.org/10.1016/j.neuropharm.2018.09.023

82. Perez Garcia G, Guzman-Quevedo O, Da Silva AR, Bolanos-Jimenez F (2016) Early malnutrition results in long-lasting impairments in patternseparation for overlapping novel object and novel location memories and reduced hippocampal neurogenesis. Sci Rep 6:21275. https://doi. org/10.1038/srep21275

83. Perez-Polo JR, Rea HC, Johnson KM, Parsley MA, Unabia GC, Xu GY, Prough D, DeWitt DS, Spratt H, Hulsebosch CE (2015) A rodent model of mild traumatic brain blast injury. J Neurosci Res 93:549-561. https://doi. org/10.1002/jnr.23513

84. Robinson ME, MCKee AC, Salat DH, Rasmusson AM, Radigan LJ, Catana C, Milberg WP, McGlinchey RE (2019) Positron emission tomography of 
tau in Iraq and Afghanistan Veterans with blast neurotrauma. Neuroimage Clin 21:101651. https://doi.org/10.1016/j.nicl.2019.101651

85. Sadeghi L, Rizvanov AA, Salafutdinov II, Dabirmanesh B, Sayyah M, Fathollahi Y, Khajeh K (2017) Hippocampal asymmetry: differences in the left and right hippocampus proteome in the rat model of temporal lobe epilepsy. J Proteomics 154:22-29. https://doi.org/10.1016/j.jprot .2016 .11 .023

86. Sajja VS, Hubbard WB, Hall CS, Ghoddoussi F, Galloway MP, VandeVord PJ (2015) Enduring deficits in memory and neuronal pathology after blast-induced traumatic brain injury. Sci Rep 5:15075. https://doi. org/10.1038/srep15075

87. Schindler AG, Meabon JS, Pagulayan KF, Hendrickson RC, Meeker KD, Cline M, Li G, Sikkema C, Wilkinson CW, Perl DP et al (2017) Blastrelated disinhibition and risk seeking in mice and combat Veterans: Potential role for dysfunctional phasic dopamine release. Neurobiol Dis 106:23-34. https://doi.org/10.1016/j.nbd.2017.06.004

88. Shi QX, Chen B, Nie C, Zhao ZP, Zhang JH, Si SY, Cui SJ, Gu JW (2020) A novel model of blast induced traumatic brain injury caused by compressed gas produced sustained cognitive deficits in rats: involvement of phosphorylation of tau at the Thr205 epitope. Brain Res Bull 157:149-161. https://doi.org/10.1016/j.brainresbull.2020.02.002

89. Shinohara Y, Hosoya A, Yamasaki N, Ahmed H, Hattori S, Eguchi M, Yamaguchi S, Miyakawa T, Hirase H, Shigemoto R (2012) Right-hemispheric dominance of spatial memory in split-brain mice. Hippocampus 22:117-121. https://doi.org/10.1002/hipo.20886

90. Shumyatsky GP, Malleret G, Shin RM, Takizawa S, Tully K, Tsvetkov E, Zakharenko SS, Joseph J, Vronskaya S, Yin D et al (2005) stathmin, a gene enriched in the amygdala, controls both learned and innate fear. Cell 123:697-709

91. Sims R, Hill M, Williams J (2020) The multiplex model of the genetics of Alzheimer's disease. Nat Neurosci 23:311-322. https://doi.org/10.1038/ s41593-020-0599-5

92. Song H, Cui J, Simonyi A, Johnson CE, Hubler GK, DePalma RG, Gu Z (2018) Linking blast physics to biological outcomes in mild traumatic brain injury: Narrative review and preliminary report of an open-field blast model. Behav Brain Res 340:147-158. https://doi.org/10.1016/j. bbr.2016.08.037

93. Steimer T (2011) Animal models of anxiety disorders in rats and mice: some conceptual issues. Dialogues Clin Neurosci 13:495-506

94. Stocker RP, Cieply MA, Paul B, Khan H, Henry L, Kontos AP, Germain A (2014) Combat-related blast exposure and traumatic brain injury influence brain glucose metabolism during REM sleep in military veterans. Neuroimage 99C:207-214. https://doi.org/10.1016/j.neuroimage 2014.05.067

95. Strigo IA, Spadoni AD, Lohr J, Simmons AN (2014) Too hard to control: compromised pain anticipation and modulation in mild traumatic brain injury. Transl Psychiatry 4:e340. https://doi.org/10.1038/tp.2013.116

96. Sullivan RM, Dufresne MM, Siontas D, Chehab S, Townsend J, Laplante F (2014) Mesocortical dopamine depletion and anxiety-related behavior in the rat: sex and hemisphere differences. Prog Neuropsychopharmacol Biol Psychiatry 54:59-66. https://doi.org/10.1016/j.pnpbp .2014 .05 .002

97. Tashev R, Stefanova M (2015) Hippocampal asymmetry in angiotensin II modulatory effects on learning and memory in rats. Acta Neurobiol Exp (Wars) 75:48-59

98. Tate DF, York GE, Reid MW, Cooper DB, Jones L, Robin DA, Kennedy JE, Lewis J (2014) Preliminary findings of cortical thickness abnormalities in blast injured service members and their relationship to clinical findings. Brain Imaging Behav 8:102-109. https://doi.org/10.1007/s1168 2-013-9257-9
99. Thijssen EH, La Joie R, Wolf A, Strom A, Wang P, laccarino L, Bourakova $\checkmark$, Cobigo Y, Heuer H, Spina S et al (2020) Diagnostic value of plasma phosphorylated tau181 in Alzheimer's disease and frontotemporal lobar degeneration. Nat Med 26:387-397. https://doi.org/10.1038/ s41591-020-0762-2

100. Tronson NC, Corcoran KA, Jovasevic V, Radulovic J (2012) Fear conditioning and extinction: emotional states encoded by distinct signaling pathways. Trends Neurosci 35:145-155. https://doi.org/10.1016/j. tins.2011.10.003

101. Turner RC, Lucke-Wold BP, Logsdon AF, Robson MJ, Dashnaw ML, Huang JH, Smith KE, Huber JD, Rosen CL, Petraglia AL (2015) The quest to model chronic traumatic encephalopathy: a multiple model and injury paradigm experience. Front Neurol 6:222. https://doi. org/10.3389/fneur.2015.00222

102. Vakhtin AA, Calhoun VD, Jung RE, Prestopnik JL, Taylor PA, Ford CC (2013) Changes in intrinsic functional brain networks following blastinduced mild traumatic brain injury. Brain Inj 27:1304-1310. https://doi. org/10.3109/02699052.2013.823561

103. Vieweg WV, Julius DA, Fernandez A, Beatty-Brooks M, Hettema JM, Pandurangi AK (2006) Posttraumatic stress disorder: clinical features, pathophysiology, and treatment. Am J Med 119:383-390

104. Wang Y, Mandelkow E (2016) Tau in physiology and pathology. Nat Rev Neurosci 17:5-21. https://doi.org/10.1038/nrn.2015.1

105. Warden DL, French LM, Shupenko L, Fargus J, Riedy G, Erickson ME, Jaffee MS, Moore DF (2009) Case report of a soldier with primary blast brain injury. Neuroimage 47(Suppl 2):T152-153. https://doi. org/10.1016/j.neuroimage.2009.01.060

106. Winer JA, Chernock ML, Larue DT, Cheung SW (2002) Descending projections to the inferior colliculus from the posterior thalamus and the auditory cortex in rat, cat, and monkey. Hear Res 168:181-195

107. Yolken RH, Jones-Brando L, Dunigan DD, Kannan G, Dickerson F, Severance E, Sabunciyan S, Talbot CC Jr, Prandovszky E, Gurnon JR et al (2014) Chlorovirus ATCV-1 is part of the human oropharyngeal virome and is associated with changes in cognitive functions in humans and mice. Proc Natl Acad Sci USA 111:16106-16111. https://doi.org/10.1073/ pnas. 1418895111

108. Yuan W, Barber Foss KD, Dudley J, Thomas S, Galloway R, DiCesare C, Leach J, Scheifele P, Farina M, Valencia G et al (2019) Impact of low-level blast exposure on brain function after a one-day tactile training and the ameliorating effect of a jugular vein compression neck collar device. J Neurotrauma 36:721-734. https://doi.org/10.1089/neu.2018.5737

109. Zhang B, Carroll J, Trojanowski JQ, Yao Y, Iba M, Potuzak JS, Hogan AM, Xie SX, Ballatore C, Smith AB 3rd et al (2012) The microtubule-stabilizing agent, epothilone $\mathrm{D}$, reduces axonal dysfunction, neurotoxicity, cognitive deficits, and Alzheimer-like pathology in an interventional study with aged tau transgenic mice. J Neurosci 32:3601-3611. https://doi. org/10.1523/JNEUROSCI.4922-11.2012

\section{Publisher's Note}

Springer Nature remains neutral with regard to jurisdictional claims in published maps and institutional affiliations. 